\title{
Labor Market Concentration, Earnings, and Inequality
}

\author{
Kevin Rinz*
}

\begin{abstract}
I document trends in local industrial concentration from 1976 through 2015 and estimate effects of concentration on earnings outcomes. Local concentration generally declined over that period, unlike national concentration, which declined sharply in the early 1980s before increasing to nearly its original level beginning around 1990. Increased local concentration reduces earnings and increases inequality. Because average concentration has fallen, the 90/10 earnings ratio was six percent lower and earnings one percent higher in 2015 than they would have been if local concentration were at its 1976 level. Most demographic subgroups experience mean earnings reductions, and all experience increases ininequality.
\end{abstract}

Keywords: Monopsony, labor market concentration, industrial concentration, local labor markets, earnings, earnings inequality

JEL Classification Codes: J31, J42

\footnotetext{
${ }^{*}$ Kevin Rinz is an economist at the U.S. Census Bureau. Email: kevin.rinz@census.gov. The author declares that he has no relevant or material financial interests that relate to the research described in this paper. This paper has been reviewed by the U.S. Census Bureau to ensure that no policy views are expressed within it. The data used in this paper cannot be published but are available through the Federal Statistical Research Data Centers (FSRDCs). For more information, contact the author or your local FSRDC administrator. Any opinions and conclusions expressed herein are those of the author and do not necessarily reflect the views of the U.S. Census Bureau. All results have been reviewed to ensure that no confidential information is disclosed. The statistical summaries reported in this paper have been cleared by the Census Bureau's Disclosure Review Board, release authorization numbers CBDRB-FY18-469, CBDRB-FY18-496, CBDRB-FY19-139, and CBDRB-FY2020-CES005-029. This paper includes an online appendix. The author thanks Zach Brown, Anne Case, Martha Gimbel, Javier Miranda, Lee Tucker, Victoria Udalova, John Voorheis, Abigail Wozniak, and seminar participants at the Census Bureau, Colby College, the Bureau of Labor Statistics, and the Sundance Conference on Monopsony in Labor Markets for helpful comments and discussions.
} 


\section{Introduction}

The idea that employers are not simply price-takers in the labor market but may have the power to set their workers' wages is old, but the possibility that monopsony power could have substantial influence on economic outcomes has received renewed attention of late. ${ }^{1}$ This attention comes as various measures of concentration and market power at the national level increase alongside stagnant wage growth and a declining labor share of income (Autor et al., 2017; De Loecker and Eeckhout, 2017; Edmond et al., 2018; Grullon et al., 2019; Hall, 2018; Traina, 2018). Policymakers have also taken an interest in the subject, with the White House Council of Economic Advisers highlighting competition issues generally and monopsony in particular in issue briefs (2016a; 2016b).

Empirically, research has identified a wide variety of settings in which monopsony power may be relevant to workers' economic outcomes. These include specific labor markets, such as markets for teachers (Landon and Baird, 1971; Luizer and Thornton, 1986; Falch, 2010; Ransom and Sims, 2010), nurses (Staiger et al., 2010; Matsudaira, 2014), engineers (Fox, 2010), retail workers (Ransom and Oaxaca, 2010; Dube et al., 2018b), judicial clerks and medical residents (Priest, 2010), and professional baseball players (Humphreys and Pyun, 2015); Amazon’s Mechanical Turk platform (Dube et al., 2017, 2018a); the franchise sector (Krueger and Ashenfelter, 2018); and historical settings such as turn-of-the-century coal mining (Boal, 1995) and sharecropping (Naidu, 2010). There is also growing evidence that imperfect competition in the labor market is broadly applicable beyond the specific institutional settings of particular labor markets (Manning, 2010, 2011; Azar et al., 2017; Dube et al., 2017; Tucker, 2017; Azar et al., 2018; Martins, 2018). Some of this broader work focused on recent years has found high levels of concentration in local labor markets, one potentially important source of monopsony power. ${ }^{2}$ This fact, in combination with increases in national measures of market power, fueled

\footnotetext{
${ }^{1}$ Smith (1776) describes a "tacit, but constant and uniform combination” among employers to control workers' wages. Robinson (1933) formalized the case of wage-setting power arising from there being a single buyer of labor in a market, coining the term "monopsony."

${ }^{2}$ Other potential sources include search frictions, preference heterogeneity, and policies such as non-compete and
} 
speculation that local concentration has been increasing over time. However, research had not provided evidence on this possibility, in part because of the difficulty of obtaining suitable data for investigating it.

In this paper, I document trends in local labor market concentration in the United States between 1976 and 2015 using the Longitudinal Business Database (LBD). To the extent that employment concentration is relevant to workers' labor market outcomes, local concentration is likely to be particularly important because most workers do not engage in geographically wideranging job searches. ${ }^{3}$ I define local labor markets as intersections between industries and geographies, focusing primarily on four-digit North American Industry Classification System (NAICS) industries within commuting zones. ${ }^{4}$ I measure concentration using the HerfindahlHirschman Index, constructed using employment.

Trends in local industrial employment concentration have differed substantially from trends in national industrial employment concentration over the last four decades. While mean national industrial concentration declined sharply in the early 1980s, it began increasing rapidly again around 1990 and continued to do so until the onset of the Great Recession, nearly returning to its initial level. Local industrial concentration, on the other hand, has been declining fairly consistently since 1976, with limited interruptions. By 2015, average local concentration had declined to about three quarters of its 1976 value. This is a striking fact given that recent interest in monopsony was initially motivated in part by increases in national measures of firm power.

The divergence between local and national industrial concentration is not sensitive to the industrial classification scheme, geographic definition of local, level of industrial aggregation, or use of employment weights. The divergence appears to be driven by the behavior of large, nation- ally dominant firms. Over time, these firms have both expanded operations into additional local

no-poaching agreements. See, among others, Manning (2003); U.S. Department of the Treasury (2015); Krueger and Ashenfelter (2018); Starr et al. (2018) for more.

${ }^{3}$ Job seekers are much more likely to apply to vacancies closer to their homes (Marinescu and Rathelot, 2018), with only about a quarter looking outside their state of residence (Sinclair, 2014).

${ }^{4} \mathrm{I}$ use the 1990 vintage of commuting zones throughout this analysis. 
markets and increasingly operated in the same local markets as each other. This pattern has led industrial concentration to rise when measured nationally (large firms’ expansion into new markets increased their share of national employment) but fall when measured locally (increased likelihood of direct local competition among these firms makes it more difficult to dominate a specific local market). A counterfactual exercise that varies components of national and local trends in isolation suggests a smaller role in their divergence for changes in the composition of employment across industries and little role for geographic reallocation of employment.

The broad theoretical applicability of employer wage-setting power, its demonstrated empirical relevance, and the increased salience of competition, concentration, and market power issues more broadly have led some to consider it a possible contributing factor in the rise of inequality over the last few decades (Council of Economic Advisers, 2016b). The periods during which inequality and measures of market power such as markups have risen overlap significantly. At the same time, income mobility has at best stagnated (Chetty et al., 2016).

Changes in monopsony power may also have effects that vary across groups of workers. Webber (2015) found that increased employer power in the labor market increases inequality in the overall earnings distribution, but did not consider heterogeneity on other dimensions such as demographic characteristics. Others have considered the effects of monopsony power on specific subgroups of workers, finding, for example, that it reduces the wages of immigrants in Germany (Hirsch and Jahn, 2015) and various subgroups in Portugal (Martins, 2018), increases the gender wage gap in both Germany (Hirsch et al., 2010) and the United States (Webber, 2016), and reduces the wages of skilled workers and trainees in Switzerland (Muehlemann et al., 2013).

Here, I combine comprehensive administrative data on firms and individuals with demographic information obtained from surveys to consider distributional effects of local industrial concentration on earnings and inequality within and across demographic groups, using the substantial variation across markets in the magnitude of changes in local industrial concentration over time.

When estimating with OLS, I find a small, positive relationship between concentration and 
earnings between 2005 and 2015. Given that a variety of local supply or demand shocks could affect both employment concentration and earnings, I also instrument for local concentration in a given local labor market using the average local concentration experienced in other places by workers in the same industry. Consistent with other recent research, I find that increased concentration reduces earnings. My estimates imply that moving across markets from the median to the 75th percentile of the employment-weighted local industrial concentration distribution would reduce earnings by about ten percent. A typical within-market increase in concentration over this period would have reduced earnings by about one percent.

I also find that the effects of concentration vary across groups of workers. First, looking across the earnings distribution, I find that increased concentration leads to greater inequality as measured by the ratio of the 90th percentile of the earnings distribution to the 10th percentile. About 60 percent of the increase in the 90/10 earnings ratio comes from increased distance between the median and the 10th percentile. Lower percentiles are more negatively affected by changes in concentration than are percentiles in the middle of the distribution. Percentiles higher in the distribution change little in response to changes in concentration. ${ }^{5}$

While these estimates indicate that increased concentration reduces earnings and increases inequality, combining them with the changes in concentration that have actually been observed since 1976 suggests that local labor market concentration specifically has not been a major contributing factor to broader changes in inequality and earnings growth. According to back-of-the-envelope calculations, average annual real earnings were about 1.2 percent higher and the 90/10 earnings ratio about 6.3 percent lower in 2015 than they would have been if local concentration were at its 1976 level.

The availability of demographic information from survey and administrative data sources allows me to evaluate whether the effects of local industrial concentration vary across groups defined

${ }^{5}$ My estimates are consistent with Webber (2015), in which a similar analysis was performed using individual-level unconditional quantile regressions. 
by individual characteristics. I find that the effects of concentration on average earnings are negative across most groups defined by age, race, sex, and education. The groups for which the earnings effect point estimate is positive are women and Black workers, though the estimate for Black workers is not statistically significant. Notably, these groups have historically experienced significant labor market discrimination in the United States, and changes in related behaviors could rationalize positive market-level earnings effects for these groups.

All demographic groups experience increases in inequality when concentration increases. Men, older workers, and workers with high school diplomas or less see the largest increases in the 90/10 earnings ratio. As in the overall distribution, these increases are generally driven by the bottom of the distribution. Women and Black workers are again exceptions, with virtually all of the inequality increases in these groups coming from the top half of the distribution. This could be due in part to the fact that these groups generally have lower earnings throughout the distribution. As a result, changes experienced at any given point in the overall earnings distribution are experienced further up the distribution of earnings within these groups.

This rest of this paper proceeds as follows. Section II discusses measurement issues and describes the data I will use to investigate these questions. Section III lays out trends in local industrial concentration over four decades. Section IV describes my approach to estimating the effects of local industrial concentration on earnings and inequality. Section V reports results, and Section VI discusses them and concludes.

\section{Measurement and Data}

Two important questions must be answered before considering trends in local labor market concentration or the effects of concentration on earnings and inequality. First, what constitutes a local labor market? This is, of course, a question of very broad interest, and resolving it is well beyond the scope of this paper. Fundamentally, the definition should capture the set of reasonable potential 
employers for a given worker. Common approaches to defining local labor markets include using geographies such as county or commuting zone, job characteristics such as industry or occupation, or interactions among these to define local labor markets. There are important limitations to these approaches, since the relevance of geography, industry, and occupation may differ across types of workers. ${ }^{6}$ Recent work has also used job-to-job flows, networks, and other similar approaches to identify the outside options available to specific workers and consider how the nature of those "markets" differs across types of workers (e.g. Nimczik 2018; Caldwell and Danieli 2018; Caldwell and Harmon 2019; Jarosch et al. 2019; Schubert et al. 2019). Exposure and response to concentration may also differ across types of workers. Here, I use interactions between industry and geography to define local labor markets. I discuss this further and provide some evidence on differences in exposure to concentration below.

Second, how can we measure local labor market concentration and the outcomes of interest? Some business data are available publicly, but they do not provide firm-level information with fine geographic detail, limiting their usefulness for measuring local employment concentration. As for outcomes, few local labor markets are sufficiently well represented in surveys to construct reliable distributional statistics. Fortunately, I can address both of these issues using administrative records available through the U.S. Census Bureau. The Bureau's data linkage infrastructure also allows me to construct earnings measures that incorporate demographic information available from the American Community Survey (ACS), the 2000 and 2010 decennial censuses, and the Census Numident file. The rest of this section details the relevant datasets and how they figure into my analysis.

\footnotetext{
${ }^{6}$ Retail workers, for example, may be primarily focused on opportunities close to their current location when looking for new jobs, while researchers might prioritize jobs in their preferred occupations that are located in a variety of potentially distant places.
} 


\section{A The Longitudinal Business Database}

The Longitudinal Business Database (LBD) provides key information such as employment, payroll, location, industry, and firm affiliation on an annual basis for all employer establishments in the United States (Jarmin and Miranda, 2002). Data, which are compiled from the Business Register (BR), the Economic Census, and other surveys, are available annually from 1976 and cleaned to facilitate easy linking over time, with the database containing one observation per establishment per year. I use data through 2015.

The availability of firm identifiers, in combination with employment, industry, and geography information, permits the construction of firm-based measures of employment concentration within industry-by-geography cells. ${ }^{7}$ As these cells are intended to approximate labor markets here, there are some conceptual questions about what the appropriate levels of aggregation are when constructing these measures. For example, what level of geographic aggregation is appropriate? Previous studies of local labor markets have used areas as small as counties and as large as states, as well as intermediate constructions such as metropolitan areas and commuting zones. Empirically determining the ideal construction of local labor markets is beyond the scope of this paper; I use commuting zones as my preferred geographic unit. ${ }^{8}$

The appropriate level of industrial aggregation is also an open question. In product markets, using more precise industrial classifications probably identifies more reasonable sets of close competitors, but does this also identify more reasonable sets of alternative employment opportunities for workers? Could human capital be transferable across reasonably fine industry categories to a greater degree than the goods or services produced by those industries are substitutable for each other? This is an empirical question that I leave to future work. I use the four-digit NAICS industry codes, an intermediate level of classification, in my analysis here. ${ }^{9}$

\footnotetext{
${ }^{7}$ The LBD does not contain any information on employment byoccupation.

${ }^{8}$ As discussed below, my results are not sensitive to the choice of commuting zones vs. counties or four-digit vs. three-digit industries to define markets.

${ }^{9}$ In my data, about 71 percent of workers employed in a given four-digit NAICS industry in a given year still work in that industry the next year. This, of course, includes many workers who have not changed employers. Among those
} 
Since this paper includes regression analysis that relies on within-industry variation, I standardize industry codes over time using a set of crosswalks developed by Fort and Klimek (2018). Rather than generating aggregate correspondences between industry codes over time or assign establishments in industries that split by randomizing, Fort and Klimek construct their crosswalks at the establishment level, taking advantage of the longitudinal nature of the LBD to bridge the transition from SIC to NAICS, resolve ambiguous re-classifications, and generate consistent industry codes. I obtain the Fort-Klimek industry code from the most recent available year for each establishment and use it to classify that establishment in all years of its operation.

To be explicit about my baseline analysis, I define local labor markets as commuting zonelevel, standardized, four-digit NAICS industries. Some of these decisions certainly affect the level of concentration in a market (smaller geographies or more specific industries tend to be more concentrated than a larger geographies/less specific industries), but as I show below, comparisons between national and local trends in industrial concentration are little changed when constructed using contemporaneous industrial classifications instead of the consistent Fort-Klimek industry codes, or when constructed using three-digit (instead of four-digit) NAICS industries, or when constructed using counties instead of commuting zones. ${ }^{10}$

who do change employers, about 25 percent remain in the same industry. This may seem low, but estimates from the Current Population Survey indicate that, among job-changers observed employed with valid industry information in consecutive months, only about 45 percent remain in the same "detailed industry," a classification with only 52 distinct categories, far fewer than the roughly 300 four-digit NAICS industries. Moreover, occupational mobility in the CPS is similarly high. Only about half of job-changers remain in the same "detailed occupation," a classification with 23 distinct categories. This similarity suggests that even though occupation may have a more intuitive connection to a worker's hypothetical labor market, the relationship between a worker's industry at their current and next jobs is comparably strong to the relationship between their occupation at their current and next jobs. Moreover, recent work has shown that recent aggregate trends in occupational concentration track trends in industrial concentration. For more, see Handwerker and Dey (2019); Qiu and Sojourner (2019).

${ }^{10}$ Though not reported here, interpretation of my regression results is also not sensitive to estimation based on using three-digit vs. four-digit NAICS industries or counties vs. commuting zones to define markets. These results are available upon request. 


\section{B Other Data}

I obtain information on people's earnings from Form W-2. The available extract includes a limited set of items from the universe of W-2 filings from 2005 through 2015. The earnings measure I use is the sum of wage and salary income plus deferred compensation, the broadest measure that can be constructed from the available data. The EINs listed on W-2s allow me to assign people to industries using their highest-paying employer each year. I identify people’s geographic locations using data from Form 1040 tax returns and 1099 information returns. As Table 1 shows, more than 90 percent of $\mathrm{W}-2$ forms are matchable to geography and industry information (which are necessary for the analysis to proceed) in each year of data used here. I obtain demographic information from the Census Numident, the decennial census, and the ACS. Table 1 also shows that these sources combine to provide very good coverage of age, gender, race, and ethnicity. Coverage of education is more limited (only about 15 to 21 percent of forms match to education data per year), since education information is only available from the "long form" decennial census, which was last conducted in 2000, and the ACS, which samples roughly one percent of the population each year. Additional details about my use of these datasets can be found online in Appendix A and Appendix B.

\section{Trends in Industrial Concentration}

While a few papers have considered trends in national industrial concentration, little evidence is available on how local industrial concentration has varied over time and across places. ${ }^{11}$ I provide such evidence in this section. Unless otherwise noted, estimates are constructed using employment to weight observations, so the trends described here reflect the experience of the average worker rather than the average market.

\footnotetext{
${ }^{11}$ Contemporaneous work by Lipsius (2018) also considers this question. Benmelech et al. (2018) report the national average of local concentration within five-year bins, measured using the HHI, but their analysis is focused on the manufacturing sector.
} 
Before turning to local concentration, Figure 1a presents the average HHI across national fourdigit NAICS industries from 1976 through 2015. Average concentration falls sharply in the early years of this period, declining by roughly 40 percent between 1976 and $1983 .{ }^{12}$ It then sees little change until about 1990, at which point it begins increasing, nearly reaching its 1976 level by the onset of the Great Recession. This pattern is also evident using other measures of employment concentration, such as the top-four or top-twenty firm employment concentration ratios. ${ }^{13}$

Figure 1b presents the trend in average local industrial concentration, again measured using the HHI, averaged across commuting zone by four-digit NAICS industry markets. Local concentration also declines over the late 1970s and early 1980s, though not as precipitously as national concentration. It generally continues declining, though more slowly, through the 1990s and even most of the 2000s before increasing modestly during the Great Recession. Like the national trend, this pattern is also evident in the top-four and top-twenty firm concentration ratio trends, as shown in the online appendix. ${ }^{14}$

The divergence between the national and local concentration trends is not sensitive to any of the major decisions about how the two series are constructed. As shown in Appendix C, the same pattern emerges if trends are calculated using contemporaneous industry classifications instead of consistent classifications based on Fort and Klimek (2018), if local markets are defined using counties instead of commuting zones, if they are defined using three-digit NAICS industries

\footnotetext{
${ }^{12}$ To my knowledge, other studies have not presented estimates of the average national HHI prior to 1982. Since then, trends presented here are broadly consistent with prior work (Autor et al., 2017; Grullon et al., 2019). When I estimate the national HHI trend within sectors defined by collections of two-digit NAICS industries (presented in online appendix Figures C2, C3, and C4), only the services sector exhibits an especially large decrease in concentration that aligns with the national trend. The decline in concentration within services is driven by information industries (NAICS 51), which includes telecommunications industries. AT\&T, the dominant firm in that industry, entered into a consent decree with the Department of Justice in 1982 that required it to divest itself of local telephone companies (Pinheiro, 1987). The availability of an economic explanation for the observed change in employment concentration should alleviate any concerns that the trend presented above is an artifact of a data processing or estimation error. Online appendix Figure C5 presents the trend in average national industrial concentration, excluding all four-digit NAICS industries within the information and cultural industries sector. Concentration still declines in the early to mid-1980s (though from lower level than in Figure 1a) and increases after 1990.

${ }^{13}$ See online appendix Figure C1.

${ }^{14} \mathrm{An}$ alternative local construction of this figure based on counties is presented in online appendix Figure C7 and tells a similar story.
} 
instead of four-digit industries, and if markets are not weighted by employment in constructing the average. ${ }^{15}$ It is worth noting, however, that the increase in local concentration observed since the onset of the Great Recession in the employment-weighted figures is clearer and more persistent when employment weights are not used, suggesting that smaller markets are becoming more concentrated even as the average worker is largely not exposed to those increases.

Why have the national and local concentration trends diverged? This question can be addressed both mechanically (which components of national and local mean concentration are changing differentially?) and economically (why are those components changing differentially?). I address the mechanical component of this question through a series of counterfactual exercises. First, I consider how the national trend has evolved. Average national concentration at a given point in time can be written

$$
\overline{H H I}_{t}^{N}=\sum_{i} \text { Share }_{i t} \cdot H H I_{i t}
$$

where, for industry $i$ at time $t, H H I_{i t}$ is the $\mathrm{HHI}$ within the industry and Share $i t$ is the share of national employment in that industry. Figure 2a plots the actual national trend in average HHI, as well as two counterfactual national trends: the one that would have been realized if only within industry HHIs varied over time (i.e. if industry shares of employment remained fixed at their 1976 shares), and the one that would have been realized if only industry employment shares (or, between-industry concentration) varied over time (i.e. if HHIs remained fixed at their 1976 levels). The counterfactual trend that is based on varying only within-industry HHIs is very similar to the actually observed trend. Prior to 2000, changes in industrial composition are generally moving the average in the same direction as changes in concentration, but may explain a small share of the decline, suggesting that changes in within-industry concentration are primarily responsible forthe evolution of the national trend.

Second, I perform a similar exercise on the local concentration trend. Since the national share of employment in a given market/commuting zone-industry $\left(\right.$ Share $\left._{c, i, t}\right)$ can be written as the prod-

\footnotetext{
${ }^{15}$ See online appendix figures C8 through C11.
} 
uct of the share of national employment in that commuting zone (CZShare ${ }_{c t}$ ) and the share of commuting zone employment in that industry (CZIndShare ${ }_{c i t}$ ), the average local HHI can be written

$$
\mathrm{HHI}_{t}^{L}=\sum_{c} \sum_{i} \text { CZShare }_{c t} \cdot \text { CZIndShare }_{c i t} \cdot \mathrm{HHI}_{\text {cit }}
$$

Figure 2b presents counterfactual trends analogous to those in Figure 2a that vary each of the three components of the local concentration trend in isolation: within market HHIs, within CZ industrial composition, and the share of national employment in each commuting zone. The actual local concentration trend is also presented for reference.

Based on the counterfactual trends, changes in both market HHIs and commuting zone industrial composition put downward pressure on the average local HHI, with their counterfactuals moving roughly in tandem through about 2000. After that, the concentration-only counterfactual trends slightly upward, while the composition-only mean continues to decline. Changes in the distribution of employment across commuting zones have little impact on the overall trend.

The most striking difference between the national and local counterfactuals is the behavior of the concentration-only series. After initially declining in both settings, it increases sharply after 1990 in the national series while increasing later and only modestly in the local series. Apart from roughly the second half of the 1990s in the national series, changes in industrial composition generally put downward pressure on both the national and local average HHI.

To further illustrate the implications of the divergence between the behavior of national and local HHIs, I conduct a third counterfactual exercise. Figure 2c presents two counterfactual trends: the trend that would have been realized if only local HHIs had changed, with local industrial composition and commuting zone employment distributions held fixed; and the trend that would have been realized if each local industry's HHI had evolved proportionally to that industry's national HHI. As one might expect based on the previous two exercises, these two counterfactuals are starkly different, with the trend based on the evolution of national industry HHIs increasing 
steadily after 1990, while the trend based on the evolution of local HHIs declines initially and remains lower than its starting level, similar to the actual local HHI trend. This figure makes clear that local and national HHIs have behaved very differently, especially since 1990.

But why have national and local HHIs behaved differently? Figure 3a shows the number of markets (commuting zone by four-digit NAICS industry cells) that contain at least one establishment belonging to one of the five largest firms by employment in that national industry. The reach of the largest firms has been expanding over essentially the entire time series, with the number of local markets with at least one top-five firm increased from nearly 25,000 in 1976 to nearly 45,000 in 2015. Notably, the rate of expansion accelerated during the 1990s, around the same time national HHIs began to increase sharply.

Figure $3 \mathrm{~b}$ focuses on markets containing at least one top-five firm and reports the number of top five firms competing in these markets. In 1976, just over 60 percent of markets with at least one top-five firm contained exactly one top-five firm. By 2015, that share had fallen to just over 50 percent. Notably, the bulk of the approximately ten additional percent of markets with multiple top-five firms in 2015 had three or more top-five firms, as the share of markets with two such firms was fairly stable over this period. Also, as indicated by the previous figure, those ten percent represent substantially more markets in 2015 than in 1976. Together, Figures 3a and 3b show that the largest national firms have expanded their geographic reach over the past 40 years while also increasingly entering the same local markets. The expansion of the geographic reach of these top firms accelerated around the same time that national HHIs began to increase.

This pattern of a small number of firms increasingly dominate national industries while also more directly competing with each other in the same local markets is consistent with increasing national concentration alongside stable, lower local concentration. Figures $3 c$ and $3 d$ decompose nationally and locally constructed HHIs, respectively, into the portion of the sum of squared market shares belonging to dominant national firms and the portion belonging to other firms. Dominant national firms drive both the early 1980s decline and the post-1990 increase in concentration mea 
sured nationally. Both dominant national firms and other firms have contributed to the decline in local concentration. These patterns provide suggestive evidence that this channel merits further investigation.

I now turn my attention to changes in the distribution of local industrial concentration. Figure 4 plots trends in key percentiles of the employment-weighted local HHI distribution. The box and whisker plots present the interquartile range (box) and interdecile range (whiskers), with the mean (circle) and median (horizontal line) also plotted.

The figure makes a few important features of the distribution immediately clear. First, the distribution has a long right tail; in every year, the value of the 75th percentile is more than twice that of the median, and the value of the 90th percentile is more than twice the value of the 75th percentile. As a result, the mean HHI is consistently well above the median. Second, the distribution has tightened over time, and this appears to have been driven by changes in the top of the distribution. The value of the 90th percentile has fallen by about a third between 1976 and 2015. The values of the 75th percentile and median have also fallen, but more modestly, while the 10th and 25th percentiles have seen little change in absolute terms over this period.

Returning my focus to mean local industrial concentration, I now consider possible geographic heterogeneity. Figure 5a maps the average HHI across industries within each commuting zone in 1976, and Figure 5b does the same for 2015. In both years, the areas that are most concentrated tend to be rural. In particular, the Great Plains region has a relatively large number of highly concentrated commuting zones in both 1976 and 2015. The least concentrated markets tend to be in urban areas.

Figures $5 c$ and $5 d$ show how the average concentration within each commuting zone has changed over time, mapping differences in logged HHIs between select years. The middle of the country, from Texas and New Mexico up to North Dakota and Montana is home to some of the commuting zones where markets became more concentrated at the fastest rates between 1976 and 2015, even as the national average local HHI was falling during that period. Between 2005 and 
2015, increases in concentration were more widespread, though the magnitude of these increases was generally small in percent terms. Consistent with the national trend, the larger declines in concentration during the earlier years lead to net decreases in concentration on average in most commuting zones over the full period considered. Just over half of the markets that produce these commuting zone averages also experienced declining concentration over this period, while just over 40 percent saw increased concentration.

\section{Estimation}

As illustrated in the previous section, there is a great deal of variation in industrial concentration within markets over time. To begin to assess whether those changes have effects on the earnings distribution, I produce scatter plots of changes in mean earnings and changes in industrial concentration. Figure 6 plots several highly aggregated, long-run versions of this relationship. In panel (a), the $y$-axis shows the change in the log of average earnings across industries within commuting zones between 1976 and 2015, while the x-axis plots the change in the log of the average HHI across industries within commuting zones. Earnings are approximated by dividing total payroll within industry by total employment, both obtained from the LBD. Points are presented in further aggregation as the averages within 20 bins containing equal numbers of observations.

Over this horizon and at this level of aggregation, there is a clear negative relationship between changes in industrial concentration and changes in earnings. When the same relationship is plotted at the market level (i.e. without first averaging earnings and concentration levels across industries within commuting zones), as in panel (b), the negative relationship remains clear, though the magnitude of the slope of the line of best fit falls by more than 80 percent.

The relationship between industrial concentration and earnings is also sensitive to the time frame considered. Panel (c) plots the same relationship using changes between 2005 and 2015. The relationship remains negative, but the magnitude again declines by more than 75 percent relative 
to panel (b).

During this time period, earnings can also be calculated using $\mathrm{W}-2$ data. The $\mathrm{W}-2$ earnings measure is conceptually superior to LBD measure, which divides total annual payroll by a point-in-time measure of employment. ${ }^{16}$ To the extent that the point-in-time employment measure understates total employment over the course of the year, the LBD average earnings measure overstates true average earnings. Because $\mathrm{W}-2 \mathrm{~s}$ are issued to all employees, they capture total annual compensation and total annual employment, allowing me to calculate actual average earnings. ${ }^{17}$ In panel (d), I plot this relationship using the W-2 earnings measure. The relationship between changes in earnings and changes in concentration becomes slightly positive, and its magnitude falls again. ${ }^{18}$

Similar relationships also hold in OLS regressions of the form

$$
\log \left(y_{c i t}\right)=\log \left(H H I_{c i t}\right) \alpha+\delta(c, i, t)+\varepsilon_{c i t}
$$

where, $c$ indexes commuting zones, $i$ indexes industries, $t$ indexes time, $\delta(c, i, t)$ represents a possibly interacted specification of commuting zone, industry, and time fixed effects, and $\varepsilon_{c i t}$ is noise. Estimates from these regressions are reported in Table 2. As in Figure 6, this relationship becomes weaker and ultimately turns slightly positive as I move to my preferred earnings measure in column 3, remaining positive when weights are not used in column 4 . $^{19}$

Even conditional on fixed effects or other available observable characteristics of markets,

\footnotetext{
${ }^{16}$ The LBD captures employment as of March each year.

${ }^{17}$ Another advantage of the $\mathrm{W}-2$ earnings measure is that it implicitly captures changes in earnings due to changes in labor tenure as well. If, for example, higher concentration allows firms to retain workers more selectively, leading to lower average tenure and more distinct employees over the course of the year, the W-2 earnings measure would capture this change, while the LBD earnings measure would not, necessarily. Thanks to an anonymous referee for highlighting this point.

${ }^{18}$ Online appendix Table D1 lays out, mechanically, why the sign of the OLS relationship between the change in average earnings and the change in concentration changes when switching from the LBD-based measure of earnings to the W-2-based measure in panels (c) and (d) of Figure 6. Changing measures reduces the magnitude of the negative relationship between $\mathrm{HHI}$ and total earnings by 0.031 , but this switch only reduces the magnitude of the relationship between $\mathrm{HHI}$ and total employment by 0.014 , leading to an increase in the relationship between $\mathrm{HHI}$ and average earnings of 0.017 , which is large enough to turn that relationship positive under the $\mathrm{W}-2$ measure.

${ }^{19}$ Qiu and Sojourner (2019) also find a positive relationship between concentration and compensation in OLS regressions.
} 
changes in local industrial concentration do not necessarily arise exogenously. Indeed, they often arise from other economic changes that also affect the earnings distribution. For example, if demand for labor in the oil and gas extraction industry fell in the Houston area, this could both decrease earnings and increase concentration, if smaller firms exit the market. If instead the supply of oil and gas extraction workers in Houston falls, this could increase earnings and increase concentration, if smaller firms have a harder time attracting the remaining workers. The direct effects of local labor demand or supply shocks on earnings and concentration could bias OLS estimates of the relationship between those two things in either direction.

In order to address concerns like the one just described, I employ an instrumental variables strategy similar to the one used by Azar et al. (2017). Specifically, I instrument for the HHI in each market (where a market is a commuting zone-level four-digit industry) in each year using the employment-weighted average HHI across other commuting zones within the same industry in the same year. ${ }^{20}$ Conceptually, this strategy identifies the effects of local concentration on earnings outcomes using only variation in local concentration that is predicted by the average experience of other local markets in the same industry, as reflected in the "leave one out" concentration mean. Formally, this mean can be written

$$
\mathrm{HHI}^{-c}=\frac{\sum_{\mathrm{z} /=c} H H I_{\text {zit }} \cdot}{\sum_{z}{ }_{c}{ } \mathrm{Emp}_{\mathrm{zit}}}
$$

where, $c$ is a specific commuting zone, $z$ indexes commuting zones, $i$ indexes industries, $t$ indexes time, and $E m p_{z i t}$ is employment. The first stage regression is

$$
\log \left(H H I_{c i t}\right)=\log \left({\overline{H H I_{i t}^{-}}}_{c}\right)
$$

\footnotetext{
${ }^{20}$ Note that I am constructing the instrument by averaging locally constructed HHIs for each other commuting zone with employment in the same industry, not constructing a single HHI using same-industry employment in all other commuting zones combined. The instrument is a measure of the average local concentration experienced by workers in other places, not a measure of almost-national concentration.
} 
where $c$ now indexes commuting zones, $\delta(c, i, t)$ represents a possibly interacted specification of commuting zone, industry, and time fixed effects, and $\eta_{\text {cit }}$ is noise.

The effects of concentration on earnings outcomes are estimated via

$$
\log \left(y_{c i t}\right)=\log \left(\mathrm{HHI}_{c i t}\right) \boldsymbol{b}+\delta(c, i, t)+\varepsilon_{c i t}
$$

where $y_{c i t}$ is an earnings outcome, $H H I_{c i t}$ represents fitted values from the first stage regression, and $\varepsilon_{\text {cit }}$ is noise. Standard errors are clustered at the market (i.e. industry by commuting zone) level. ${ }^{21}$ The coefficient of interest, $\boldsymbol{b}$, is the elasticity of earnings outcomes $y$ with respect to local industrial concentration. This estimate will reflect the causal effects of local industrial concentration on earnings outcomes if $\mathrm{HHI}_{i t}^{-\mathrm{c}}$ predicts $\mathrm{HHI}_{\text {cit }}$ and only influences earnings outcomes through that channel. As with the trends discussed above, all regressions are weighted by employment unless otherwise noted. ${ }^{22}$

Table 3 reports estimates from the first stage regression for various configurations of commuting zone, industry, and time fixed effects. The top panel uses LBD data from 1976 through 2015. The first column includes no fixed effects and presents the estimate from the univariate regression of the $\mathrm{HHI}$ on the instrument. As one might expect based on the construction of the instrument, the coefficient is close to one, indicating a strong positive relationship with local concentration. This relationship survives the introduction of the simplest, non-interacted set of commuting zone, industry, and time fixed effects in the second column.

\footnotetext{
${ }^{21}$ This level of clustering was selected to address the "experimental design" issue raised by Abadie et al. (2017): markets are the most direct level at which "assignment" (to exposure to a given level of concentration) is correlated across observations. However, one might also be concerned about correlation in unobservables within industries nationally rather than just within industry-commuting zones, especially given the use of an instrument that averages local HHIs within industry across almost the whole country. As one might expect, clustering standard errors at this higher level, at which there are only about 300 clusters, substantially reduces the precision on the estimates, leaving many short of statistical significance. Online appendix Table D2 reports select estimates with standard errors clustered at the four-digit NAICS industry level.

${ }^{22}$ I do not include time-varying, market-level controls for things like employment levels in my regressions because they are endogenous to the degree of concentration in a market. If, however, an employment control were included, for example, the estimates presented here would be little changed.
} 
The third column combines the commuting zone and industry fixed effects into a single "market" fixed effect, and the relationship remains strong. The fourth column increases the flexibility of the time fixed effects by interacting them with the commuting zone fixed effects, to allow for the possibility of trends that differ across regions but have common effects across industries. The co- efficient changes little from the third column. Finally, the fifth column adds market-specific linear time trends. The magnitude of the coefficient on the instrument falls by more than 40 percent, but it remains positive and highly statistically significant. Across all columns, the F-statistic associated with the instrument is lowest in the fifth column, and it is still nearly 800 .

The middle panel presents the same estimates based only on data from 2005 through 2015. The bottom panel also produces these estimates for 2005 through 2015, but limits the sample to markets in which earnings measures based on W-2 data are available. Across the more saturated specifications in columns three through five, the point estimates are smaller in magnitude but exhibit the same pattern as those in the top panel - whether year fixed effects are interacted with commuting zone fixed effects makes little difference, while adding market trends meaningfully shrinks the first-stage coefficient. These specifications continue to have strong F-statistics in both tables. The fact that the estimates in the second column have turned negative highlights the importance of focusing on within-market variation.

Columns three through five of Table 3 present potentially reasonable specifications for analyzing the effects of industrial concentration within local labor markets as I have defined them. My preferred specification, presented in the fourth column of this table, includes market and commuting zone by year fixed effects. Though the interaction of the commuting zone and year fixed effects makes very little difference in the first stage regressions, that flexibility could be important to some of the reduced form relationships considered below. Although including controls for trends that may vary across markets may be conceptually appealing, the bulk of my analysis relies on W-2 and therefore focuses on 2005 through 2015, and it can be difficult to identify the correct functional form for a trend over a relatively short time period like that. As a 
result, I prefer not to make the trends specification my default approach. ${ }^{23}$

\section{Effects of Local Industrial Concentration}

I use the instrumental variables strategy described in the previous section to estimate the effects of industrial concentration on a variety of earnings outcomes. I begin with mean earnings. I also take advantage of the $\mathrm{W}-2$ data to investigate distributional questions. Where local labor market circumstances give employers wage-setting power, that power is unlikely to be exercised uniformly over all workers. To the extent industrial concentration corresponds to employer wage-setting power, there is reason to suspect its effects might be experienced differently across the earnings distribution or across groups of workers. I consider effects of industrial concentration on earnings inequality, both in aggregate and within demographic groups defined by age, gender, race, and educational attainment.

\section{A Earnings and Inequality}

Table 4 reports estimates of the effects of industrial concentration on average earnings using various versions of my preferred specification. ${ }^{24}$ The dependent variable is the log of mean earnings, either constructed from the total payroll and employment variables in the LBD or calculated from Form W-2 data, as indicated. As mentioned above, the reported coefficients are elasticities of earnings with respect to local industrial concentration. In the first column, which uses LBD data from 1976 through 2015, the elasticity is about -0.05 and statistically significant. To put this estimate in context, Figure 4 indicates that moving between the local HHI experienced by the median worker and the 75th percentile worker (who work in very different markets) in

\footnotetext{
${ }^{23}$ I present some results based on the specification with trends in Appendix D. In practice, the signs of my estimates are robust to the inclusion of trends, and the magnitudes of the instrumental variables estimates with trends are scaled up relative to the baseline estimates due to the smaller first stage coefficient.

${ }^{24}$ Tables reporting estimates of the effect of concentration on earnings and inequality outcomes using all variations on the specifications reported in Table 3 are available in the online appendix.
} 
2015 represented approximately a threefold change in industrial concentration. This elasticity implies that the move from the median up to the 75th percentile would reduce earnings by about 15 percent. ${ }^{25}$ The typical change in concentration experienced within a market between 1976 and 2015 was much smaller. ${ }^{26}$ The 75th percentile within-market change in log concentration over this period (about +0.4 ) would reduce earnings by about two percent.

Column 2 repeats this analysis using only data from 2005 through 2015. The earnings effect declines in magnitude to just under -0.01 and loses statistical significance when estimated within this shorter period. Switching to the conceptually superior W-2 earnings measure in Column 3 increases its magnitude again to just over -0.03 , and it returns to statistical significance. This elasticity implies that the move from the local HHI experienced by the median worker up to the 75th percentile would reduce earnings by nearly ten percent. A more typical within-market increase in log concentration over this period (about +0.3 ) would reduce earnings by about one percent. ${ }^{27}$ These estimates are broadly consistent with other recent findings on the effects of labor market concentration on earnings (e.g. Azar et al. 2017; Benmelech et al. 2018).

Column 4 again repeats the analysis of the $\mathrm{W}-2$ earnings measure without weighting markets according to employment. The unweighted estimate is more than three times larger in magnitude than the weighted estimate. This suggests that the effects of concentration on earnings may be larger in smaller markets, as the overall average effect becomes larger when smaller markets are given greater relative weight. ${ }^{28}$

Next, I consider the effects of local industrial concentration on earnings inequality. Dependent

\footnotetext{
${ }^{25} \mathrm{~A}$ move down to the 25th percentile would also represent a roughly threefold change in concentration and would increase earnings by a similar amount.

${ }^{26}$ See Figure C16a in the online appendix.

${ }^{27}$ This change in concentration corresponds to the 75th percentile of within-market changes between 2005 and 2015. See Figure C17a in the online appendix.

${ }^{28}$ Online appendix Table D3 reports estimates of the effects of concentration on various earnings outcomes for large and small markets separately. Effects on mean earnings are indeed more negative in smaller markets. It is not clear, though, whether small market estimates are more negative because of the smallness of small markets per se, or because average concentration in small markets is higher and the same proportional change from a higher baseline has a larger effect.
} 
variables are constructed within local labor markets from W-2 data. In Table 5, I report estimates of the effects on key earnings percentile ratios (90/10, 50/10, and 90/50), as well as the Gini coefficient using my preferred specification. First, in column 1, higher local industrial concentration increases the 90/10 earnings ratio; the elasticity is 0.17 . I next estimate effects on the 50/10 and 90/50 earnings ratios (columns 2 and 3, respectively) to get a sense of whether the overall inequality effect is driven by changes in the top or the bottom of the distribution. The relative magnitude of the coefficients from these regressions indicates that the changes in the bottom of the distribution account for about 60 percent of the increase in the $90 / 10$ ratio; the elasticity of the $50 / 10$ ratio is about 0.11 , while the elasticity of the $90 / 50$ ratio is just under 0.07 .

Changes in earnings percentile ratios indicate that increases in concentration reduce earnings at the bottom of the distribution relative to earnings in the middle and at the top. They do not, however, reveal how earnings change in absolute terms across the distribution. The first estimates in this section show that mean earnings fall, so some portion of the distribution must see negative effects, but it is also conceivable that some regions of the distribution could see earnings increase. If monopsony rents accrue to some employees in form of, for example, bonuses to managers, values of high percentiles of the earnings distribution could increase with concentration.

Figure 7 presents the effects of local industrial concentration on key percentiles of the earnings distribution, estimated using my preferred specification. ${ }^{29}$ These estimates show that the increases in inequality revealed by the percentile ratios are driven entirely by declining values of low percentiles, not increasing values of high percentiles. An exercise using recentered influence function regressions (reported in the online appendix) suggests that nonlinearity of effects across the earnings distribution contributes to but is not primarily responsible for the more negative estimates for lower percentiles. ${ }^{30}$ Changes in the 75 th and 90 th percentiles are not distinguishable from zero;

\footnotetext{
${ }^{29}$ Tabular versions of these estimates, as well as other estimates reported in figure form, can be found online in Appendix D. That section also contains reduced for estimates for all specifications discussed here.

${ }^{30}$ Table D4 in the online appendix presents unconditional quantile partial effects estimated using recentered influence function regressions and a two percent sample of workers from the data that produced the market-level aggregates analyzed in the main estimates. The specification used is quadratic in HHI. Both the linear and
} 
increases in the 90/50 and 90/10 ratios arise almost entirely from reductions in the values of the median and the 10th percentile of the earnings distribution. Both these estimates and the percentile ratio estimates above are consistent with Webber (2015)'s individual-level unconditional quantile regression estimates.

I also consider the effect of concentration on the Gini coefficient, another commonly used measure of inequality, in column 4 of Table 5. I again find that increased concentration leads to increased inequality.

One caveat to this analysis is that the exclusion restriction discussed above may be susceptible to violation by local shocks that affect concentration and earnings outcomes across an entire industry. One might expect such shocks to be less common in the non-tradable sector, where production and provision of goods and services are more directly tied to local conditions. When I reproduce my main estimates using only industries classified as non-tradable or construction by Mian and Sufi (2014), results are similar to the baseline estimates discussed here, though somewhat larger in magnitude. These estimates are reported in Table 6.

\section{B Effects by Demographic Group}

In addition to varying across the earnings distribution, the effects of concentration may also vary across groups of workers defined by demographic characteristics. Summary measures of labor market conditions like the unemployment rate differ systematically across groups defined by age, race, sex, and education, both in levels and in changes over the business cycle. To the extent that such measures reflect systematic, pre-existing differences in employment opportunities across groups, changes in local industrial concentration may “treat” those groups with different intensities and have different effects on their earnings outcomes.

quadratic terms are substantially more negative for lower percentiles, and at each percentile, the linear term is sufficiently more negative than the quadratic term that it must drive the total effect. Note, however, that the computational and data demands of estimating local recentered influence functions for this analysis are intense and many smaller markets must be excluded, so these estimates should be thought of as reflecting conditions in relatively large markets. Thanks to an anonymous referee for suggesting this exercise. 
Figure 8a plots the effects of local industrial concentration on mean earnings by demographic groups based on my preferred specification. Estimates indicate that men, younger workers, and white workers experience more negative earnings effects than do women, prime-age and older workers, or Black workers. The earnings effect for women is in fact positive. ${ }^{31}$ High and low education workers experience similar earnings effects, though those estimates come with the caveat that they are based on far fewer individual observations, as education information is available only for individuals who responded to the ACS between 2005 and 2015 or the 2000 "long form” decennial census.

Turning to inequality outcomes, all groups of workers see statistically significant increases in the 90/10 earnings ratio due to increased local industrial concentration, as shown in Figure 8b. Point estimates are larger for men, older workers, and those with a high school diploma or less. Considering changes in the 50/10 earnings ratio (Figure 8c) alongside changes in the 90/50 earnings ratio (Figure 8d) shows that, like in the full sample, the inequality increases experienced by men, older workers, white workers, Hispanic workers, and members of both education groups are driven mostly by changes in the bottom half of the earnings distribution. Women, young workers, and Black workers, on the other hand, see changes in the top of the earnings distribution account for most of the increase in inequality they experience.

Differences in the effects of concentration on earnings outcomes across demographic groups could be realized through a combination of differential exposure to changes in concentration and

\footnotetext{
${ }^{31} \mathrm{~A}$ positive effect on mean earnings for women, combined with a negative effect on mean earnings for men implies that higher concentration reduces the earnings gender gap. This is potentially contrary to Webber (2016), which finds that employer monopsony power increases the gender earnings gap. Webber considers gender differences in the elasticity of labor supply to the firm, focusing on their relationship to search frictions faced by men and women. This paper is focused on a different source of monopsony power, concentration, which would not necessarily have the same relationship to the gender wage gap as search frictions do. Also, both sets of estimates could be consistent with the same underlying response to monopsony power, given the units of analysis used in these two studies (industry by commuting zone by year cells here and job spells in Webber). If having greater market power lets a firm not hire a marginal, relatively low-earning female worker, and that worker instead goes on to work for still-lower pay in another industry, her average quarterly earnings could fall relative to a comparable man while the earnings of the average woman employed in the industry of the firm that did not hire her could rise relative to the average man employed in the industry (by virtue of the low-earning woman having been excluded from the sample).
} 
differential responses to changes in concentration. Table 7 shows that members of different demographic groups do face different levels of concentration and changes in concentration between 2005 and 2015 on average. Some differences across groups are large in relative terms (e.g. work- ers aged 55 and older faced average concentration that was 32 percent higher than workers under 25 in 2005), but absolute differences are generally small, and the average worker in all groups considered faced fairly low levels of concentration in 2005 and 2015. While this does not rule out the possibility that differential exposure to concentration changes plays a role in group how these estimates differ across groups, it does illustrate that workers in the groups used here faced broadly similar conditions at the beginning and end of the period considered.

\section{Discussion and Conclusion}

This paper's finding that increased local labor market concentration reduces earnings is consistent with other recent findings from online job boards (Azar et al., 2017) and the manufacturing sector (Benmelech et al., 2018). My estimates of the effects of concentration on inequality are consistent with Webber (2015): when concentration increases, the gap between the top of the distribution and the middle of the distribution widens not because earnings increase at the top but because they decline in the middle. The gap between the middle and the bottom increases by more because earnings fall more at the bottom than they do in the middle. To the extent that employers in more concentrated markets have more power over workers, these estimates provide some evidence that that power may contribute to increased inequality, as the Council of Economic Advisers (2016b) suggested it might.

However, these estimates, combined with the fact that local industrial concentration has declined since 1976 indicate that it has not contributed to the increase in inequality over that period. Back-of-the-envelope calculations suggest that the average within-market 90/10 earnings ratio was percent lower and average annual earnings were 1.2 percent higher in 2015 than they would have been if average local industrial concentration had been at its 1976 level, which was 
about 36 percent higher. For context, the national 90/10 ratio increased by about 40 percent between 1976 and 2015, while average annual earnings increased by about 30 percent in real terms for prime-age workers over that period. ${ }^{32}$ Changes in concentration appear to have modestly mitigated the trend toward increased inequality rather than contributing to it.

The subgroup analyses in Section V.B suggest that the effects of local labor market concentration may vary not only across the distribution of earnings but also across demographic groups. While all groups experience increases in inequality as measured using the 90/10 earnings ratio due to increase concentration, not all groups see mean earnings decline. In particular, women see an earnings increase, and the point estimate of the earnings effect for black workers is positive, though small and not statistically significant. Notably, both groups have historically experienced labor market discrimination in the United States. Previous research has considered the interaction between monopsony power and so-called taste-based discrimination (e.g. Hirsch et al., 2010; Hirsch and Jahn, 2015; Webber, 2016; Fanfani, 2018), and changes in related employment dynamics could rationalize positive earnings effects for these groups.

Two plausible explanations arise from possible changes in the composition of employees and employers, respectively. If industrial concentration is a reasonable proxy for employers' monopsony power in the labor market, then increasing concentration could allow firms to be more selective in their hiring processes. Firms may choose to exercise that power by not hiring marginal workers from some demographic groups rather than hiring them and suppressing their wages. If inframarginal workers in those groups are higher earners, average earnings could increase mechanically as concentration increases and lower-earning marginal workers are excluded. The composition of workers could also change if demographic groups are differentially exposed to changes in

\footnotetext{
${ }^{32}$ The change in the 90/10 ratio is calculated from estimates in Proctor et al. (2016). The change in average annual earnings is estimated using publicly available microdata from the Annual Social and Economic Supplement to the Current Population Survey. The sample includes workers between ages 25 and 54 with positive earnings in the 1977 and 2016 surveys. Estimates are adjusted for inflation using the CPI-U-RS. The 1977 topcode is applied, in real terms, to the 2016 data before earnings are estimated.
} 
skill requirements associated with increased labor market concentration (Hershbein and Macaluso, 2018). Alternatively, if the composition of employers shifts toward larger firms with more established human resources practices as concentration increases, workers in these groups could benefit from institutional safeguards against pay discrimination, large-firm wage premiums, or other differences in business practices between incumbent and entrant firms. There is some evidence of a wage premium associated with modern chain retailers (Cardiff-Hicks et al., 2015). If the entry of such firms contributes to increased concentration, the associated wage premium could lead to positive effects on concentration on earnings, including in groups that commonly experience discrimination.

Beyond the context of discrimination, there are open and interesting questions about the role of changes in the distribution of firm size in realizing the effects of labor market concentration. Changes in how workers sort across firms are also potentially relevant here. These topics should receive additional attention in future work.

The effects of concentration on percentile earnings ratios for Black workers and women also differ from the aggregate pattern. For all workers, about 60 percent of the increase in the 90/10 ratio due to increases in concentration is realized below the median, but for Black workers and women, essentially the entire increase is realized above the median. Some of this could be attributable to the fact that any given percentile of the Black or female earnings distribution generally has a lower value than that same percentile in the overall distribution. Changes that affect any given point in the overall distribution therefore reach further up the distributions within these groups. Of course, other, non-mechanical factors could also be playing a role here, and further research on differential consequences of increased labor market concentration across groups of workers would be valuable. While industrial concentration is not a perfect measure of labor market concentration, the consistency between these estimates and others based on occupation suggest that it is a useful tool for thinking about this concept. Prior to this work, little was known about how industrial concentration had changed over time at the local level. The divergence between national and local trends in industrial concentration discussed in Section III highlights the importance of 
thinking about concentration at the local level. ${ }^{33}$ While both the trends and the regression estimates presented above are generally robust to alternative definitions of local labor markets, additional work on understanding the reasonable sets of alternative employment opportunities for workers and potential employees for firms could help improve our understanding of what constitutes a local labor market and how changes in conditions within certain industries, occupations, or localities might have consequences in others.

The importance of thinking about labor market concentration locally extends to lightly populated localities. The employment-weighted local industrial concentration distribution has a long right tail, even as it has been tightening for decades. On top of that, evidence from unweighted estimates suggests that the effects of concentration on earnings outcomes may be more negative in smaller markets. Future research should specifically dig more deeply into these markets where the consequences of increased concentration may be experienced more intensely by a smaller number of people with fewer alternative employment opportunities.

Of course, industrial concentration is not identically equal to labor market concentration, and even if that were a concept that could be measured perfectly, it would only serve as a proxy for monopsony power. Any given strategy will have limitations. Researchers should continue to compare estimates based on alternative approaches to identifying employer wage-setting power.

The data used in this paper also have their limitations, even as they represent some of the best available tools for considering these questions. For example, the earnings measures I focus on here are constructed from Form W-2. This form reports only wage and salary earnings. Moreover, it reports earnings from only a specific type of work arrangement. Income earned through independent contracting or as profit from a business is not captured by these data. The inability to

\footnotetext{
${ }^{33}$ In contemporaneous work, Rossi-Hansberg et al. (2018) find that national and local product market concentration trends also diverge. Using different geographic and industrial levels of aggregation than those employed here, Lipsius (2018) also finds diverging trends in local and national labor market concentration that are similar to those presented here.
} 
measure business income could make it difficult to identify the amount and recipients of monopsony rents. Researchers should work to incorporate measures of additional sources of income into future work, including sources relevant to both individuals who exert monopsony power and those seeking alternatives to employment in markets that are dominated by it. 


\section{References}

Abadie, Alberto, Susan Athey, Guido W Imbens, and Jeffrey Wooldridge. 2017. "When Should You Adjust Standard Errors for Clustering?” NBER Working Paper No. 24003.

Autor, David, David Dorn, Lawrence F Katz, Christina Patterson, and John Van Reenen. 2017. "The Fall of the Labor Share and the Rise of Superstar Firms." NBER Working Paper No. 23396.

Azar, Jose, Ioana Marinescu, and Marshall I Steinbaum. 2017. "Labor Market Concentration.” NBER Working Paper No. 24147.

_, , Marshall Steinbaum, and Bledi Taska, "Concentration in US Labor Markets: Evidence from Online Vacancy Data,” March 2018. NBER Working Paper No. 24395.

Benmelech, Efraim, Nittai Bergman, and Hyunseob Kim, "Strong Employers and Weak Employees: How Does Employer Concentration Affect Wages?,” February 2018. NBER Working Paper No. 24307.

Boal, William M, “Testing for Employer Monopsony in Turn-of-the-Century Coal Mining,” The RAND Journal of Economics, 1995, 26 (3), 519-536.

Caldwell, Sydnee and Nikolaj Harmon, "Outside Options, Bargaining, and Wages: Evidence from Coworker Networks,” January 2019. Working paper.

_ and Oren Danieli, “Outside Options in the Labor Market,” November 2018. Working paper.

Cardiff-Hicks, Brianna, Francine Lafontaine, and Kathryn Shaw, “Do Large Modern Retailers Pay Premium Wages?” ILR Review, 2015, 68 (3), 633-665. 
Chetty, Raj, David Grusky, Maximilian Hell, Nathaniel Hendren, Robert Manduca, and Jimmy Narang. 2016. "The Fading American Dream: Trends in Absolute Income Mobility Since 1940.” NBER Working Paper No. 22910.

Council of Economic Advisers. 2016. "Benefits of Competition and Indicators of Market Power."

https://obamawhitehouse.archives.gov/sites/default/files/page/files/20160414_cea_competition _issue_brief.pdf.

_. 2016. "Labor Market Monopsony: Trends, Consequences, and Policy Responses." https://obamawhitehouse.archives.gov/sites/default/files/page/files/20161025_monopsony_lab or_mrkt_cea.pdf.

Dube, Arindrajit, Alan Manning, and Suresh Naidu. 2017. "Monopsony and Employer Misoptimization Account for Round Number Bunching in the Wage Distribution.” Working paper.

_, Jeff Jacobs, Suresh Naidu, and Siddharth Suri. 2018. "Monopsony in Online Labor Markets.” NBER Working Paper No. 24416.

_, Laura Giuliano, and Jonathan S Leonard. 2018. "Fairness and Frictions: The Impact of Unequal Raises on Quit Behavior.” NBER Working Paper No. 24906.

Edmond, Chris, Virgiliu Midrigan, and Daniel Yu Xu. 2018. “How Costly are Markups?” NBER Working Paper No. 24800.

Falch, Torberg. 2010. “The Elasticity of Labor Supply at the Establishment Level.” Journal of Labor Economics 28(2), 237-266.

Fanfani, Bernardo. 2018. “Tastes for Discrimination in Monopsonistic Labour Markets.” Working Paper. 
Fort, Teresa C and Shawn D Klimek. 2018. "The Effects of Industry Classification Changes on US Employment Composition.” CES Working Paper 18-28.

Fox, Jeremy T. 2010. “Estimating the Employer-Switching Costs and Wage Responses of Forward- Looking Engineers.” Journal of Labor Economics 28(2), 357-412.

Grullon, Gustavo, Yelena Larkin, and Roni Michaely. 2019. “Are U.S. Industries Becoming More Concentrated?” Review of Finance 23(4), 697-743.

Hall, Robert E. 2018. "New Evidence on the Markup of Prices Over Marginal Costs and the Role of Mega-Firms in the US Economy.” NBER Working Paper No. 24574.

Handwerker, Elizabeth Weber and Matthew Dey. 2019. "Megafirms and Monopsonists: Not the same employers, not the same workers.” Working paper.

Hershbein, Brad and Claudia Macaluso. 2018. "Labor Market Concentration and the Demand for Skills.” Working paper.

Hirsch, Boris and Elke J Jahn. 2015. “Is There Monopsonistic Discrimination against Immigrants?” ILR Review 68(3), 501-528.

_, Thorsten Schank, and Claus Schnabel. 2010. "Differences in Labor Supply to Monopsonistic Firms and the Gender Pay Gap: An Empirical Analysis Using Linked Employer-Employee Data from Germany.” Journal of Labor Economics 28(2), 291-330.

Humphreys, Brad R and Hyunwoong Pyun. 2015. "Monopsony Exploitation in Professional Sport: Evidence from Major League Baseball Position Players, 2000-2011.” West Virginia University Department of Economics Working Paper 15-48.

Jarmin, Ron S and Javier Miranda. 2002. "The Longitudinal Business Database." https://www.census.gov/ces/pdf/CES-WP-02-17.pdf. 
Jarosch, Gregor, Jan Sebastian Nimczik, and Isaac Sorkin. 2019. “Granular Search, Market Structure, and Wages.” Working paper, available https://sites.google.com/site/isaacsorkin/jnsgranular.pdf?attredirects $=0$.

Krueger, Alan B and Orley Ashenfelter. 2018. “Theory and Evidence on Employer Collusion in the Franchise Sector.” IZA Discussion Paper No. 11672.

Landon, John H and Robert N Baird. 1971. "Monopsony in the Market for Public School Teachers.” American Economic Review 61(5), 966-971.

Lipsius, Ben. 2018. “Labor Market Concentration does not Explain the Falling Labor Share.” https://ideas.repec.org/p/jmp/jm2018/pli1202.html.

Loecker, Jan De and Jan Eeckhout. 2017. “The Rise of Market Power and the Macroeconomic Implications.” NBER Working Paper No.23687.

Luizer, James and Robert Thornton. 1986. “Concentration in the Labor Market for Public School Teachers.” ILR Review 39(4), 573-584.

Manning, Alan. 2003. Monopsony in Motion: Imperfect Competition in Labor Markets, Princeton University Press.

_. 2010. “The Plant Size-Place Effect: Agglomeration and Monopsony in Labour Markets.” Journal of Economic Geography 10(5), 717-744.

_. 2014. "Imperfect Competition in the Labor Market.” Handbook of Labor Economics 4 (Part B), 973-1041.

Marinescu, Ioana and Roland Rathelot. 2018. "Mismatch Unemployment and the Geography of Job Search.” American Economic Journal: Macroeconomics 10(3), 42-70. 
Martins, Pedro S. 2018. "Making their own weather? Estimating employer labour-market power and its wage effects.” Center for Globalization Research Working Paper 95.

Matsudaira, Jordan D. 2014. "Monopsony in the Low-wage Labor Market? Evidence from Minimum Nurse Staffing Regulations.” Review of Economics and Statistics 96(1), 92-102.

Mian, Atif and Amir Sufi. 2014. "What explains the 2007-2009 drop in employment?” Econometrica 82(6), 2197-2223.

Muehlemann, Samuel, Paul Ryan, and Stefan C Wolter. 2013. “Monopsony Power, Pay Structure, and Training.” ILR Review 66(5), 1097-1114.

Naidu, Suresh. 2010. "Recruitment Restrictions and Labor Markets: Evidence from the Postbellum U.S. South.” Journal of Labor Economics 28(2), 413-445.

Nimczik, Jan Sebastian. 2018. “Job Mobility Networks and Endogenous Labor Markets.” Working paper.

Pinheiro, John. 1987. “AT\&T Divestiture \& the Telecommunications Market,” Berkeley Technology Law Journal 2(2), 303-355.

Priest, George L. 2010. “Timing 'Disturbances’ in Labor Market Contracting: Roth’s Findings and the Effects of Labor Market Monopsony.” Journal of Labor Economics 28(2), 447-472.

Proctor, Bernadette D, Jessica L Semega, and Melissa A Kollar. 2016. "Income and Poverty in the United States: 2015.” Technical Report, U.S. Census Bureau.

Qiu, Yue and Aaron J Sojourner. 2019. “Labor Market Concentration and Labor Compensation.” Working paper, available http://dx.doi.org/10.2139/ssrn.3312197.

Ransom, Michael R and David P Sims. 2010. “Estimating the Firm’s Labor Supply Curve in a “New Monopsony” Framework: Schoolteachers in Missouri.” Journal of Labor Economics 28(2), 331-355. 
_ and Ronald L Oaxaca. 2010. "New Market Power Models and Sex Differences in Pay." Journal of Labor Economics 28(2), 267-289.

Robinson, Joan. 1933. The Economics of Imperfect Competition. London: Macmillan.

Rossi-Hansberg, Esteban, Pierre-Daniel Sarte, and Nicholas Trachter. 2018. "Diverging Trends in National and Local Concentration.” NBER Working Paper No. 25066.

Schubert, Gregor, Anna Stansbury, and Bledi Taska. 2019. "Mitigating Monopsony: Occupational Mobility and Outside Options.” Working paper.

Sinclair, Tara M. 2014. "Where People Search for Jobs: Cross-Border Labor Mobility Report.” Indeed Hiring Lab.

Smith, Adam. 1776. An Inquiry into the Nature and Causes of the Wealth of Nations.

Staiger, Douglas O, Joanne Spetz, and Ciaran S Phibbs. 2010. "Is there Monopsony in the Labor Market? Evidence from a Natural Experiment.” Journal of Labor Economics 28(2), 211-236.

Starr, Evan, Justin Frake, and Rajshree Agarwal. 2018. “Mobility Constraint Externalities.” Working paper.

Traina, James. 2018. “Is Aggregate Market Power Increasing? Production Trends Using Financial Statements.” Working Paper, available https://dx.doi.org/10.2139/ssrn.3120849.

Tucker, Lee. 2017. “Monopsony for Whom? Evidence from Brazilian Administrative Data.” Working paper, available http://leetucker.net/docs/LeeTucker_JMP_latest.pdf.

U.S. Department of the Treasury. 2015. “Non-compete Contracts: Economic Effects and Policy Implications.” https://www.treasury.gov/resource-center/economicpolicy/Documents/UST\%20Non-competes\%20Report.pdf. 
Webber, Douglas A. 2015. “Firm Market Power and the Earnings Distribution.” Labour Economics 35, 123-134.

_. 2016. "Firm-Level Monopsony and the Gender Pay Gap.” Industrial Relations: A Journal of Economy and Society 55(2), 323-345. 


\section{Figures}

Figure 1: Trends in Industrial Concentration, 1976-2015

(a) HHI constructed within nation four-digit NAICS industry

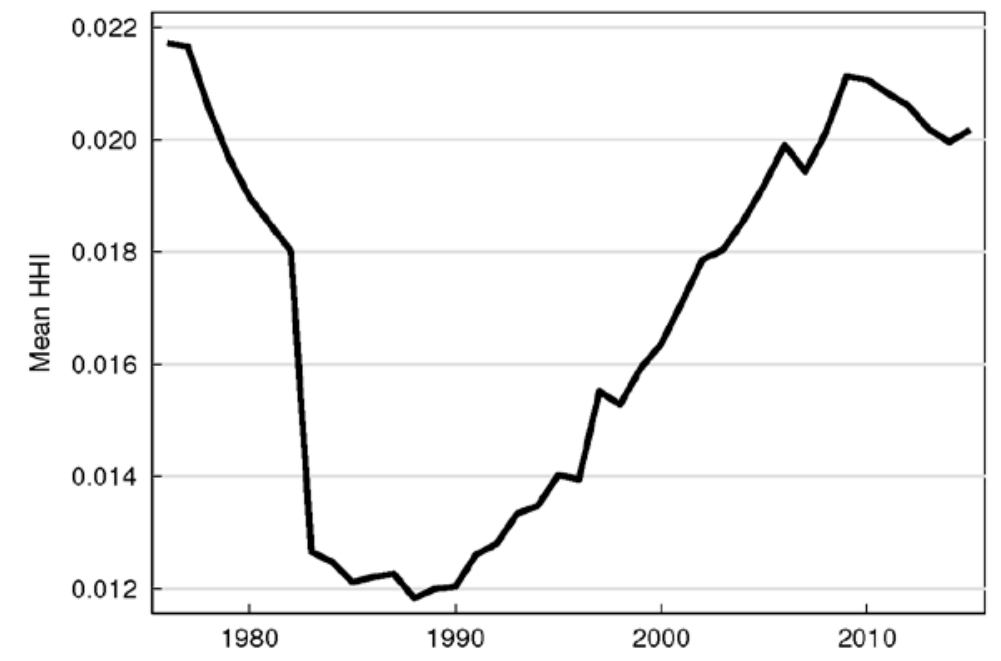

(b) HHI constructed within commuting zone by four-digit NAICS industry

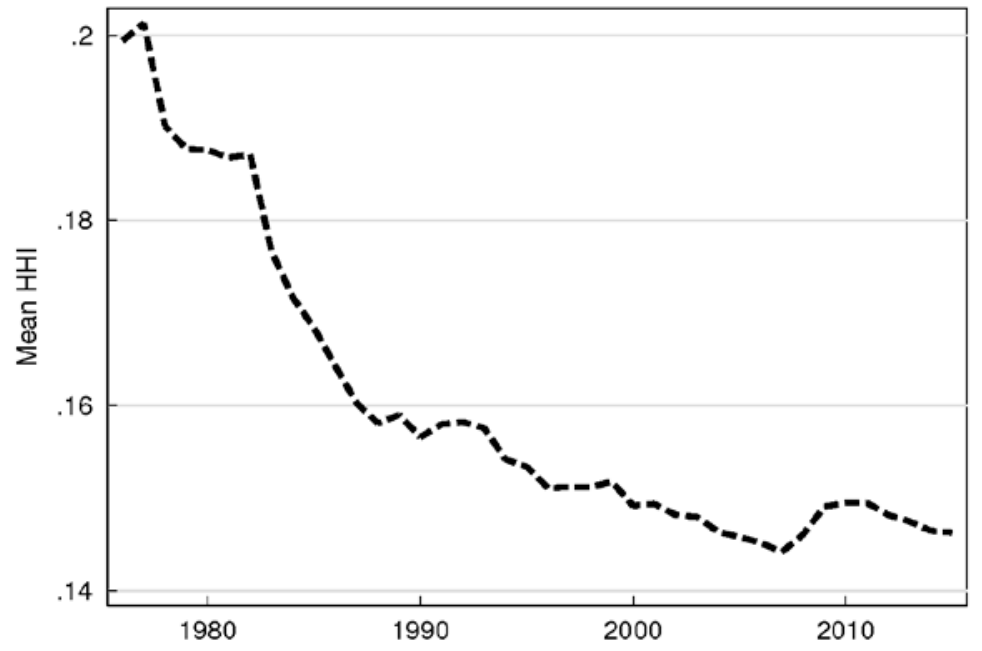

Source: Longitudinal Business Database, 1976-2015

Note: Figure plots the mean Herfindahl-Hirschman Index across national four-digit NAICS industries in panel (a) and commuting zone-level four-digit NAICS industries in panel (b), with industries standardized according to Fort and Klimek (2018), for each year from 1976 through 2015. Means are calculated using total market employment as weights. 
Figure 2: Decomposition of Industrial Concentration Trends, 1976-2015

(a) National Concentration

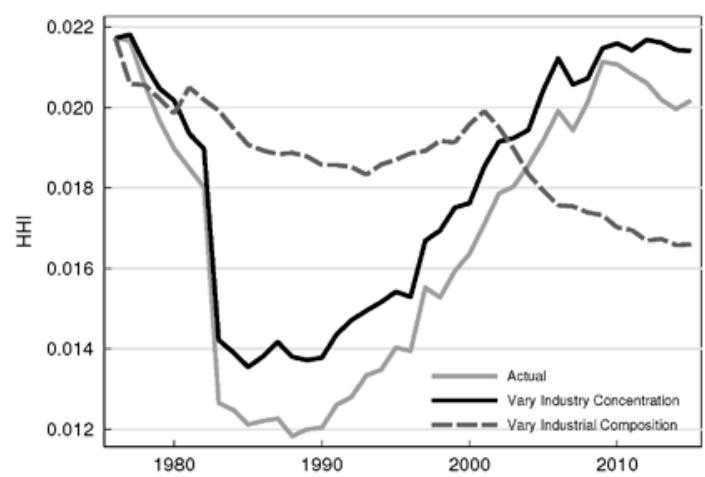

(b) Local Concentration

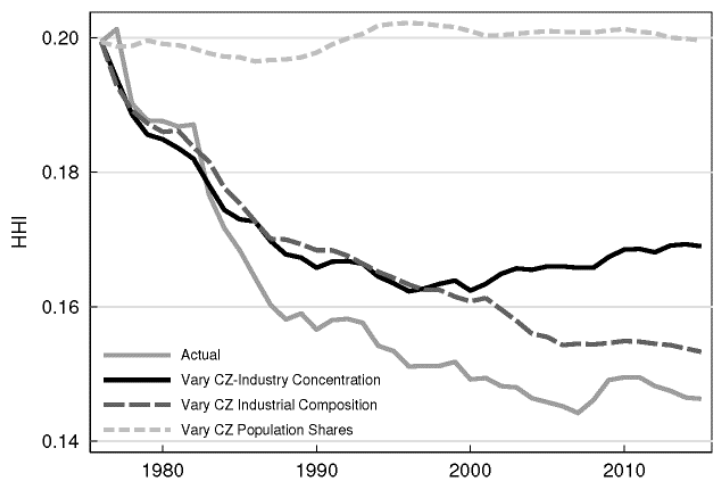

(c) Local Concentration under Alternative Assumptions

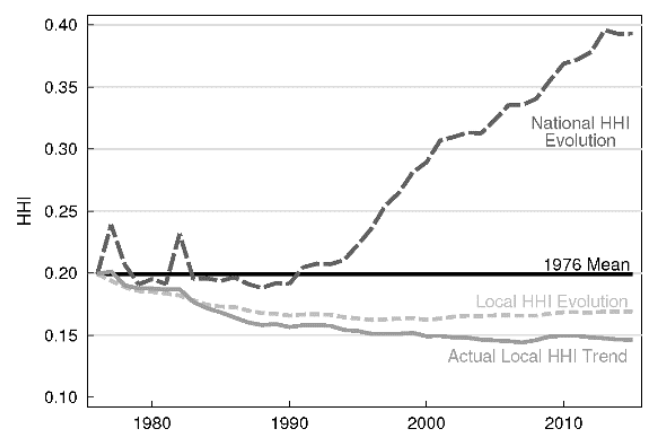

Source: Longitudinal Business Database, 1976-2015

Note: Figure plots the mean Herfindahl-Hirschman Index across national or local four-digit NAICS industries as indicated. Solid gray lines plot the actual observed trend in industrial concentration. In panels (a) and (b), the solid black lines plot the trend that would have been observed if only industrial concentration varied, and the dark gray dashed lines plot the trend that would have been observed if only industrial composition varied. In panel (b), the light gray dashed line plots the trend that would have been observed if only the distribution of employment across commuting zones varied. Panel (c) plots counterfactual local concentration trends that would have been realized under various assumptions. See Section III for details. 
Figure 3: Large Firms and the Divergence between National and Local Concentration Trends

(a) Markets with At Least One Top-5 Firm

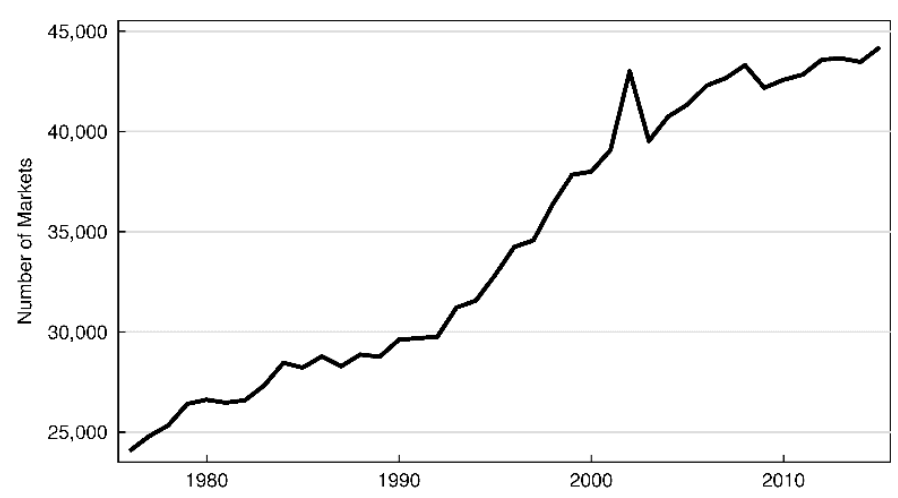

(c) National concentration decomposition

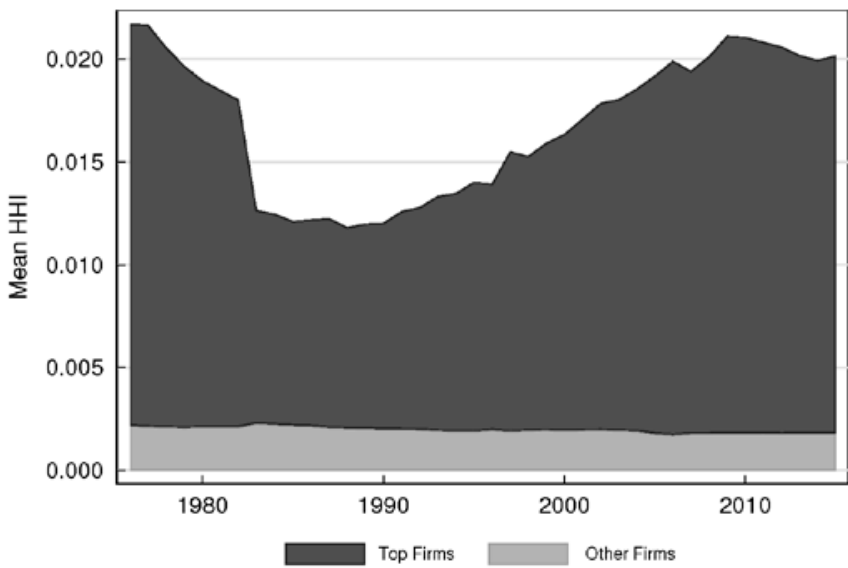

(b) Share of Markets with Multiple Top-5 Firms

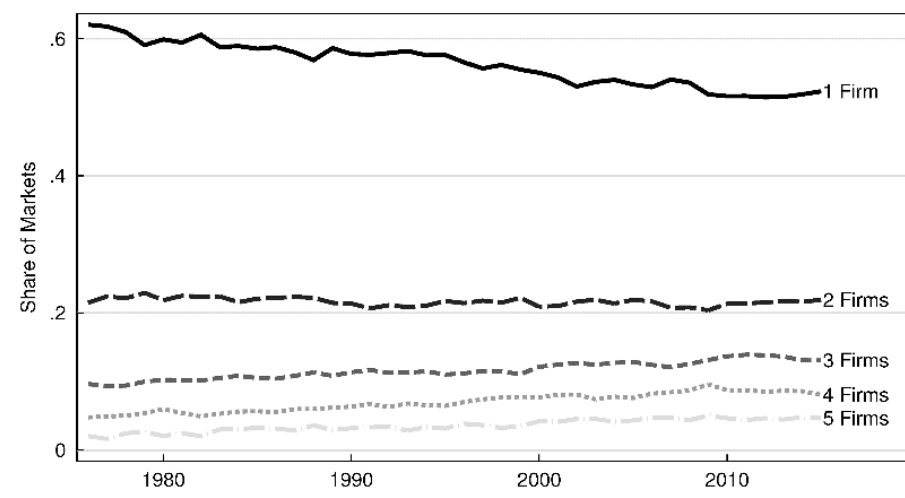

(d) Local concentration decomposition

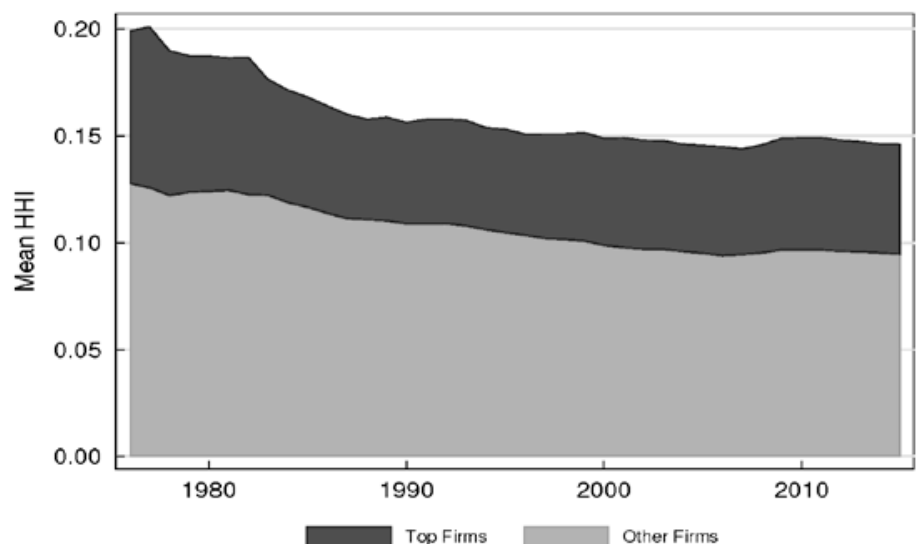

Source: Longitudinal Business Database, 1976-2015

Note: Panel (a) reports the number of markets (commuting zone-level four-digits NAICS industries) that contain at least one establishment belonging to at least one of the five largest firms by national employment within that four-digit NAICS industry. Panel (b) reports the share of markets (commuting zonelevel four-digits NAICS industries) containing at least $\mathrm{N}$ top-five national firms, conditional on containing at least one such firm. Panels (c) and (d) report trends in national and local concentration, respectively, estimated with and without the top 5 firms by employment within each national industry. 
Figure 4: Distributional Trends in Local Industrial Concentration

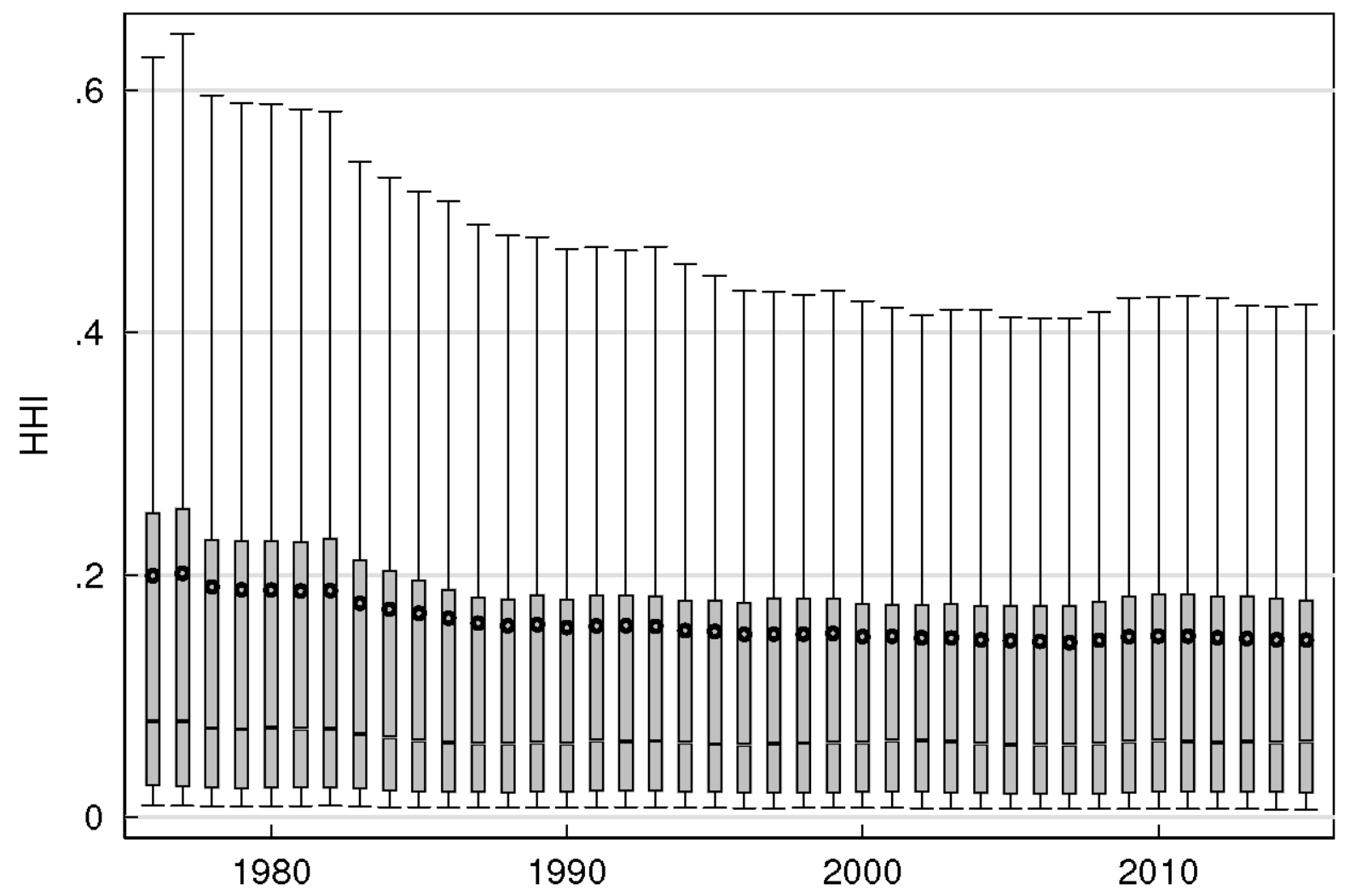

Source: Longitudinal Business Database, 1976-2015

Note: Figure plots trends in the mean and key percentiles of the local industrial concentration distribution, as measured using the Herfindahl-Hirschman Index. The unit of analysis is the commuting zone-level four-digit NAICS industry. The black circles represent the mean. The boundaries of the box in the box and whisker plots represent the 25th and 75th percentiles of the distribution, while the whiskers represent the 10th and 90th percentiles. Percentiles are approximated using the mean value of markets surrounding the actual percentile value. Percentile values are the mean value for markets within a given percentile. All values are calculated using total market employment as weights. 
Figure 5: Average Concentration Across Industries within Commuting Zones

(a) 1976

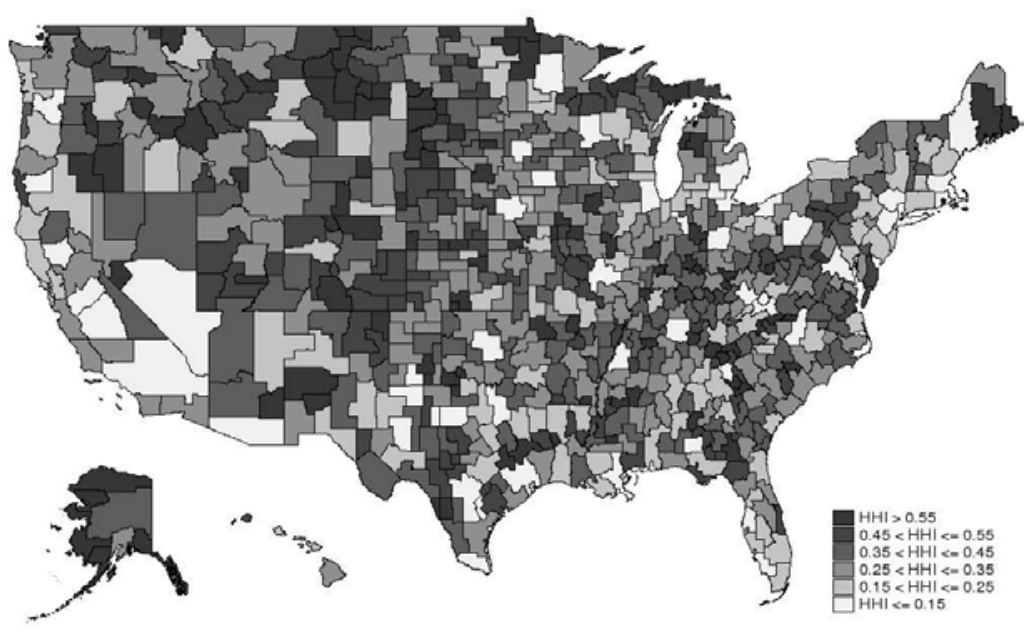

$\triangleq$

(c) Change, 1976-2015

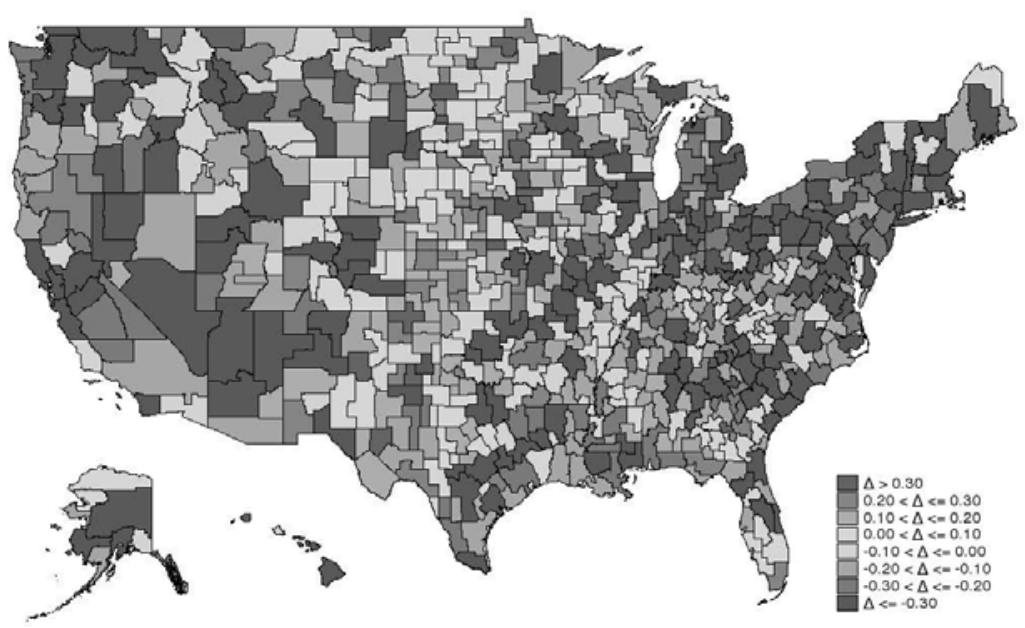

(b) 2015

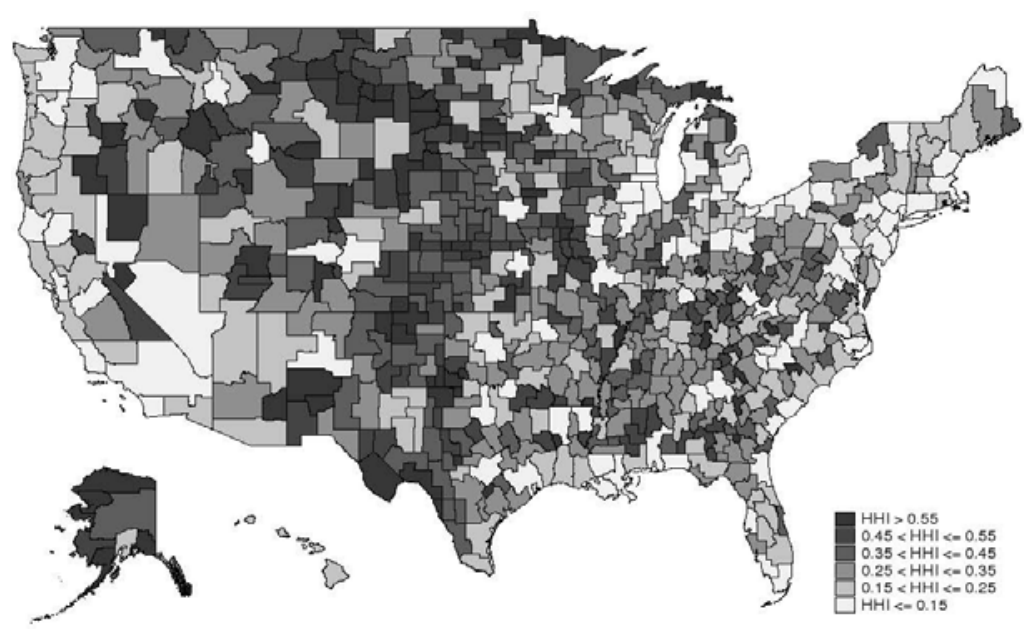

(d) Change, 2005-2015

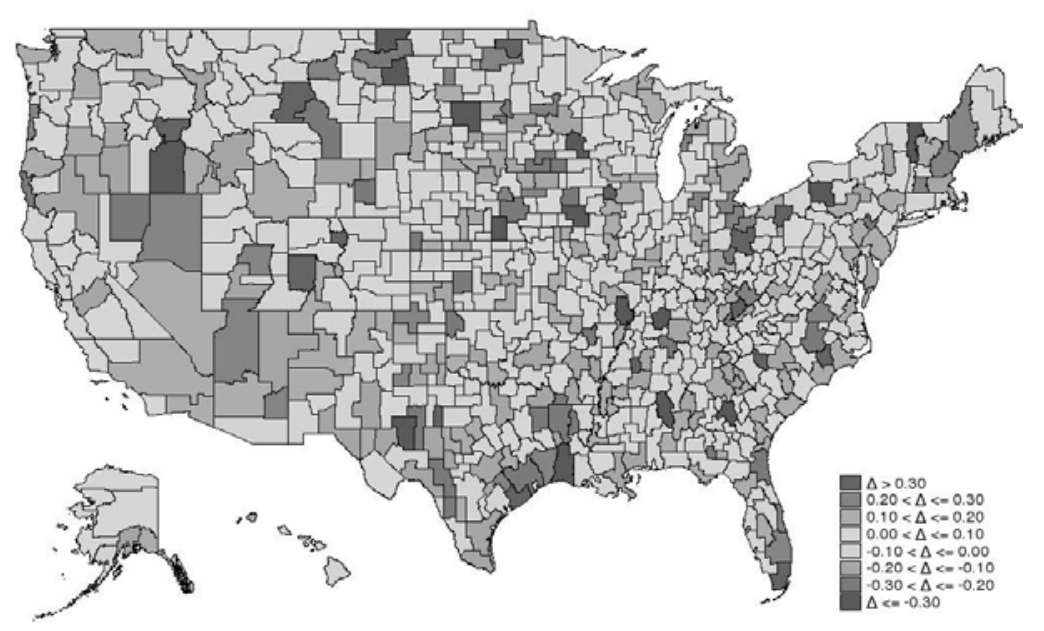

Source: Longitudinal Business Database, 1976, 2005, and 2015

Note: Map plots the level of or change in the average HHI (represented by $\Delta$ in the legend) across four-digit NAICS industries within each commuting zone, as indicated. Each commuting zones has had random noise drawn from a Laplace distribution with parameter $\varepsilon=15$ added to its true value before being categorized. 
Figure 6: Changes in Mean Earnings versus Changes in Log Mean Industrial Concentration

(a) LBD Earnings, CZ Level, 1976-2015

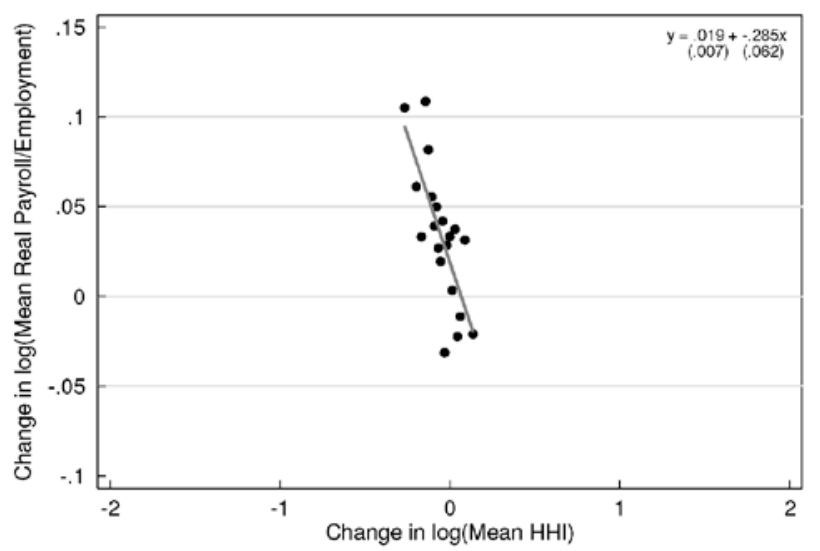

(c) LBD Earnings, CZ-Industry Level, 2005-2015

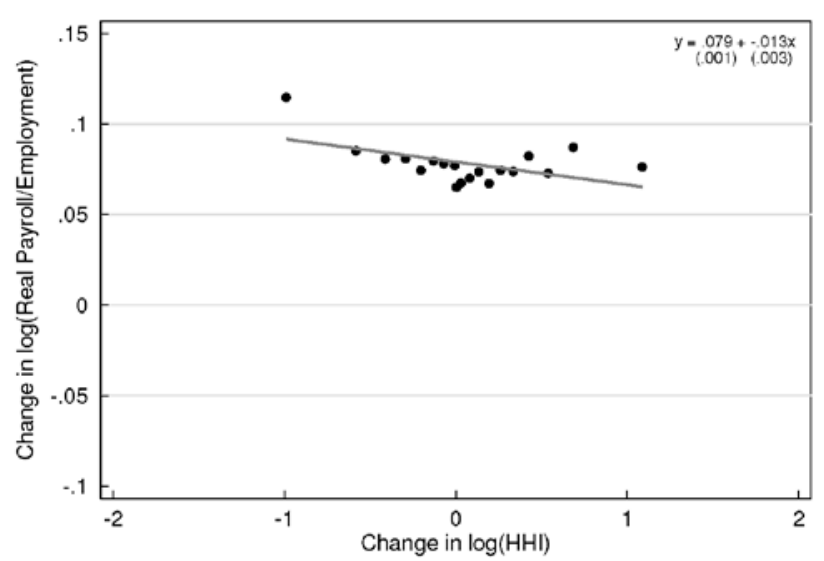

(b) LBD Earnings, CZ-Industry Level, 1976-2015

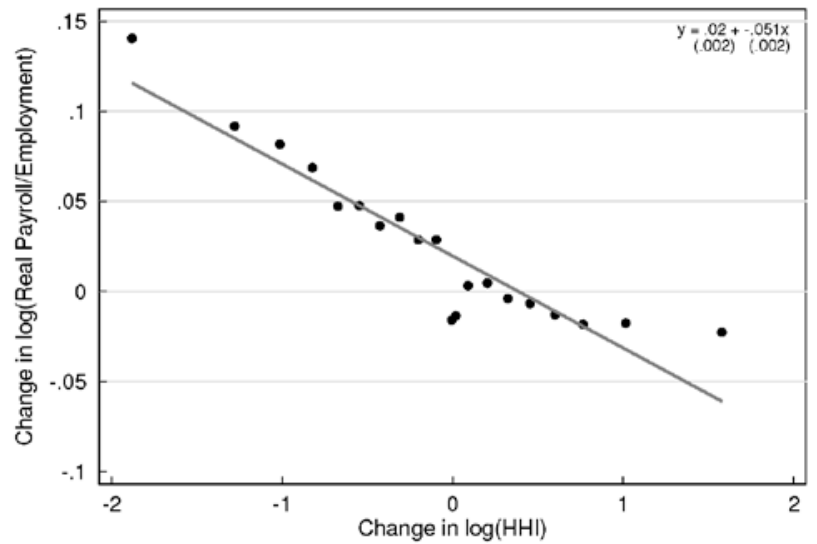

(d) W-2 Earnings, CZ-Industry Level, 2005-2015

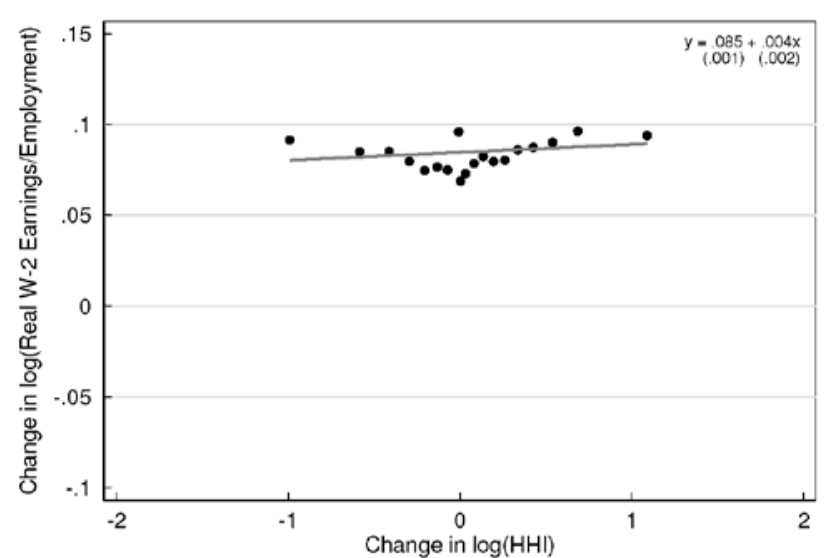

Source: Longitudinal Business Database and Form W-2, 1976, 2005, and 2015

Note: Figures plot changes in mean earnings against changes in local industrial concentration between the indicated years. Changes are calculated at the indicated level and then aggregated into twenty equal-sized bins, divided according the values of the change in industrial concentration. Earnings are obtained from the LBD in panels (a), (b), and (c), and from Form W-2 in panel (d). 
Figure 7: Effects of Industrial Concentration on Key Percentiles of the Earnings Distribution

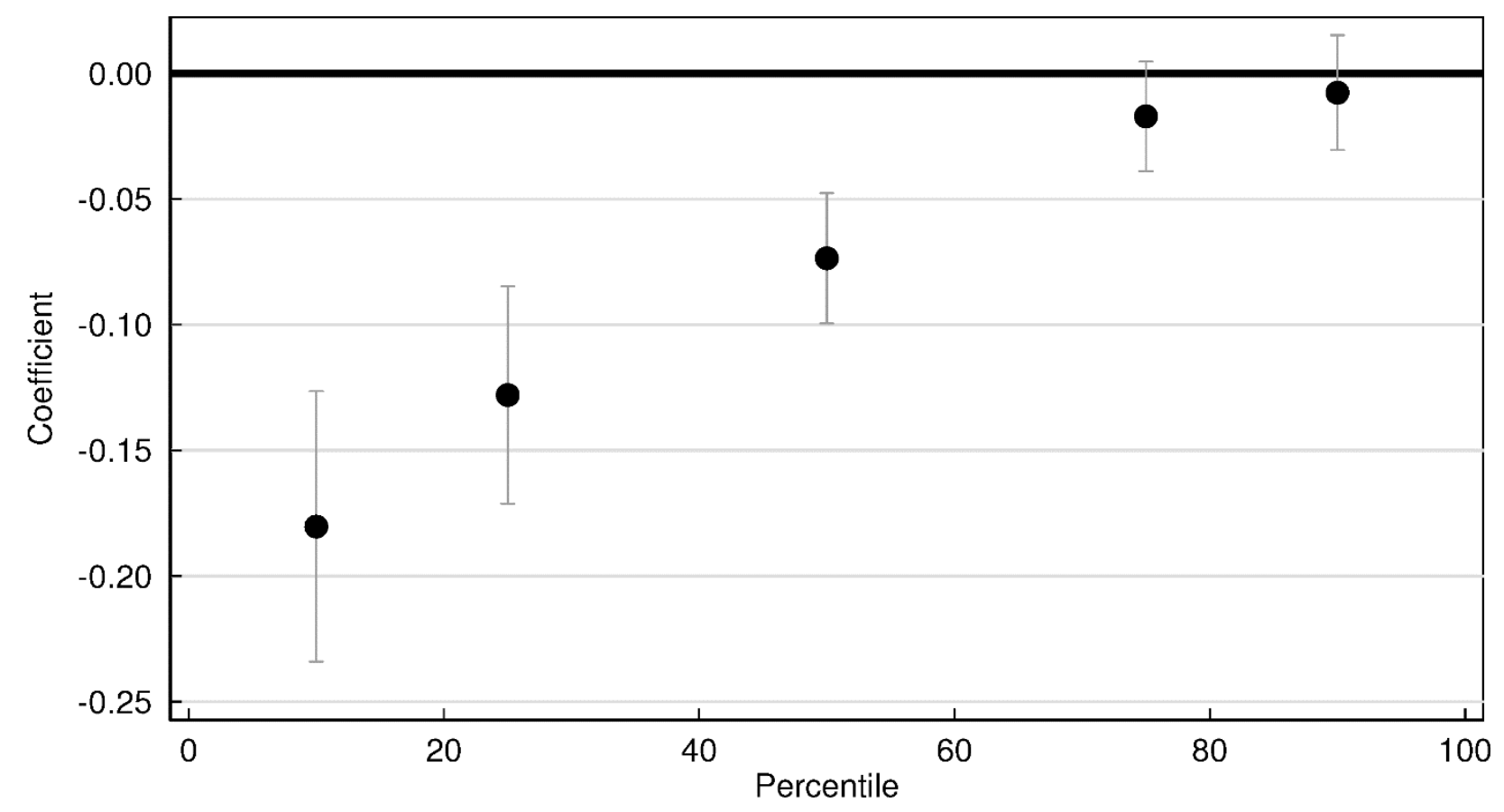

Source: Longitudinal Business Database and Form W-2, 2005-2015

Note: Figure plots regression coefficients and 95 percent confidence intervals from mean regressions of the log of the values of key percentiles of the earnings distribution within markets on the log of local industrial concentration as measured by the HHI. Regressions include market and commuting zone by year fixed effects. Regressions are employment-weighted. Coefficients represent elasticities. 
Figure 8: Effects of Industrial Concentration on Earnings Outcomes, by Demographic Group

(a) $\log ($ Mean Earnings)

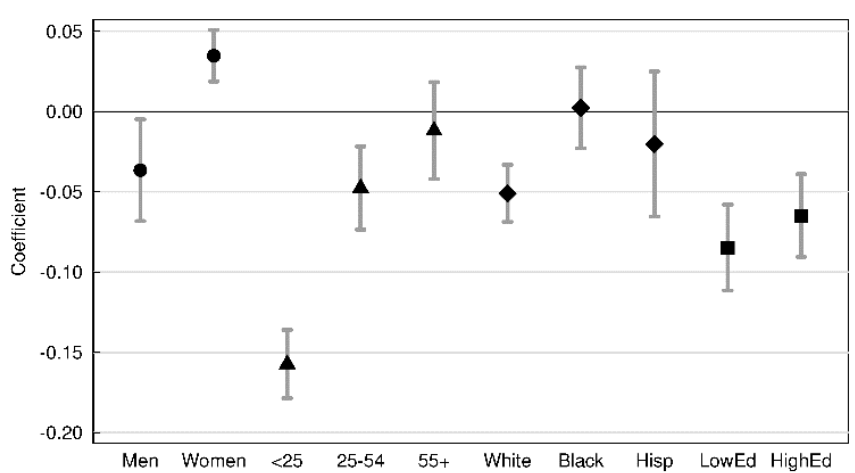

(c) $\log (50 / 10$ Earnings Ratio)

$\stackrel{A}{\perp}$

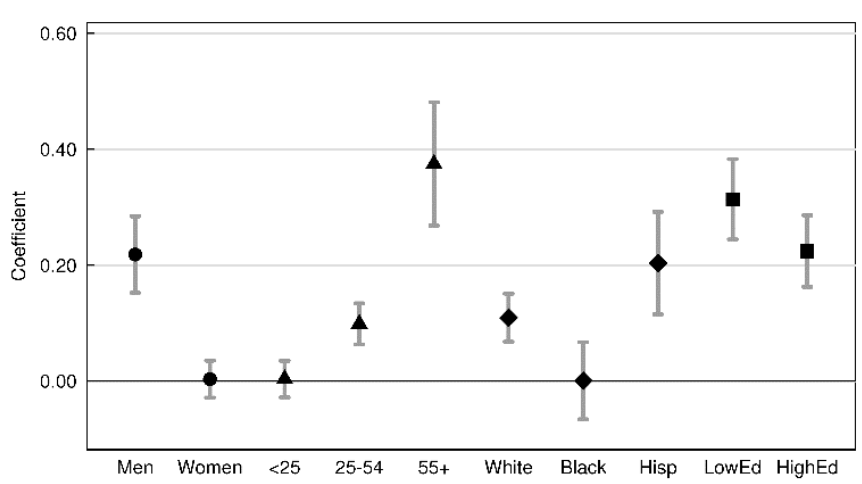

(b) $\log (90 / 10$ Earnings Ratio)

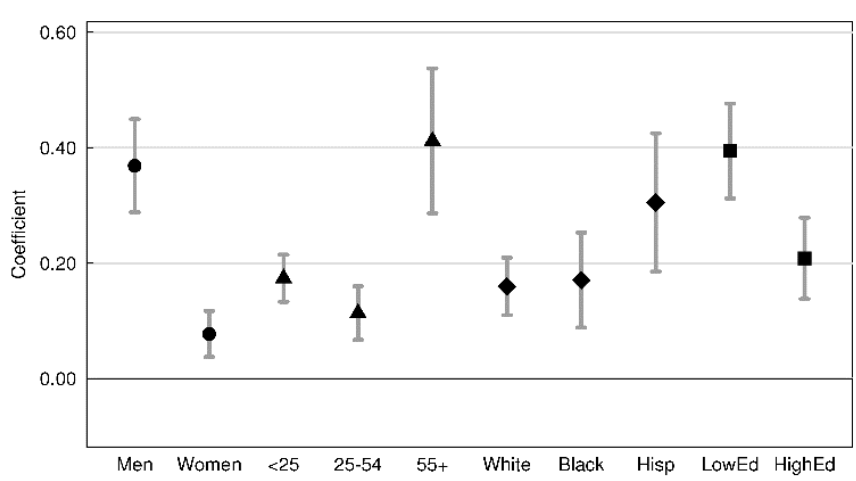

(d) $\log (90 / 50$ Earnings Ratio)

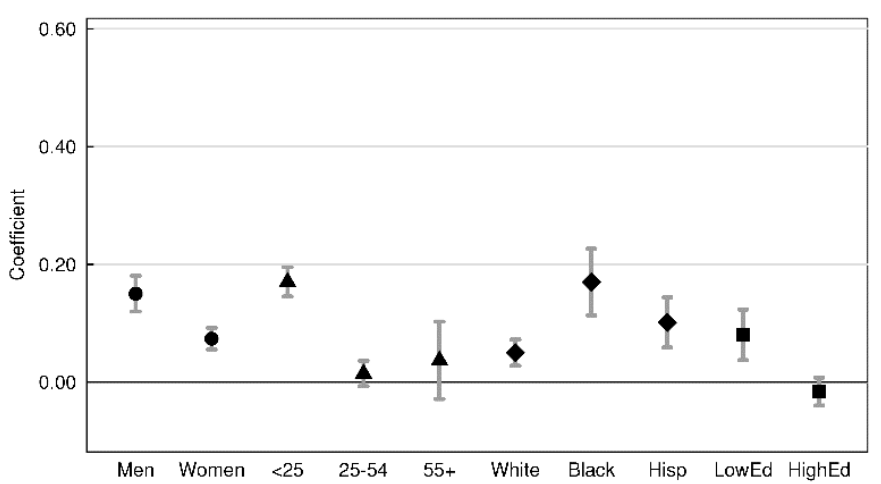

Source: Longitudinal Business Database, Form W-2, and American Community Survey, 2005 through 2015; Decennial Census, 2000 and 2010; Census Numident.

Note: Figure plots regression coefficients and 95 percent confidence intervals from mean regressions of the indicated outcome within markets on the log of local industrial concentration as measured by the $\mathrm{HHI}$ for demographic groups identified on the $\mathrm{x}$-axis. Regressions include market and commuting zone by year fixed effects. Regressions are employment-weighted. Coefficients represent elasticities. The White and Black categories refer to non-Hispanic White and non-Hispanic Black. The "Hisp" category includes Hispanics of any race. The "LowEd" category includes individuals with a high school diploma or less, while the "HighEd" category includes individuals who have at least attended some college. 


\section{Tables}

Table 1: W-2 Match Counts

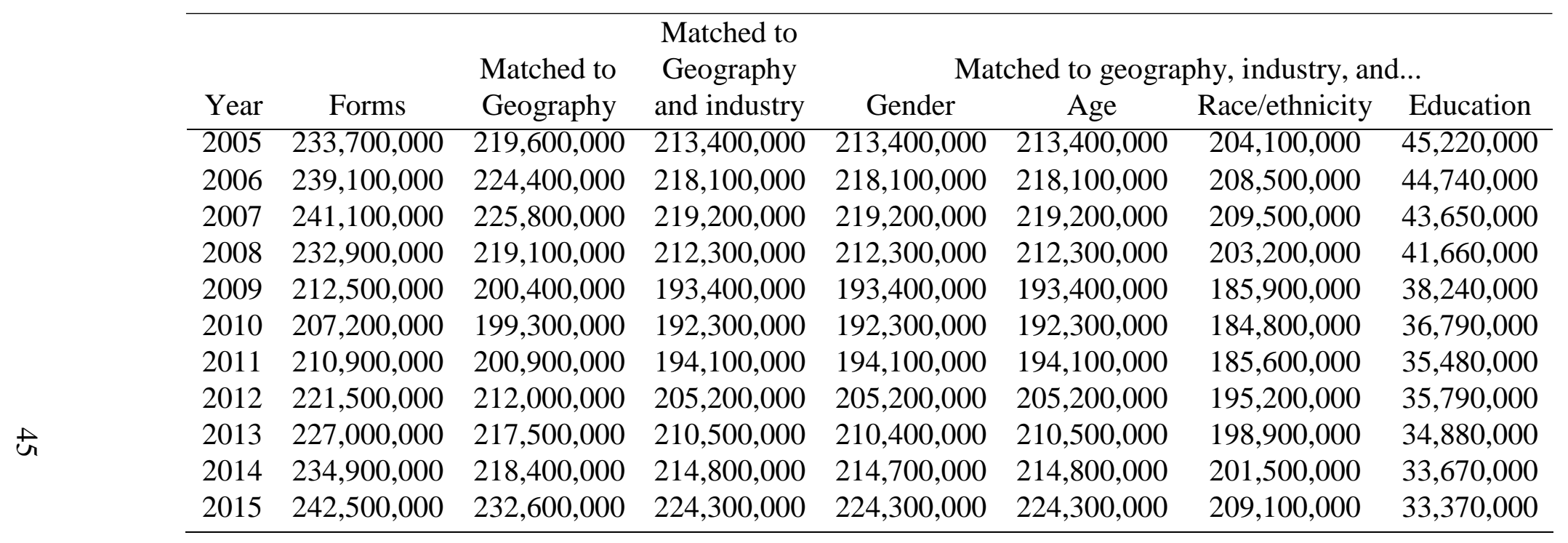

Source: Longitudinal Business Database, Form W-2, and American Community Survey, 2005 through 2015; Decennial Census, 2000 and 2010; Census Numident.

Note: Estimates have been rounded for disclosure avoidance. 
Table 2: Effects of Industrial Concentration on Earnings, OLS Estimation

\begin{tabular}{lcccc}
\hline VARIABLES & $(1)$ & $(2)$ & $(3)$ & $(4)$ \\
\hline $\log (\mathrm{HHI})$ & & & & \\
& $-0.108^{* * *}$ & $-0.0561^{* * *}$ & $0.00645^{* * *}$ & $0.00742^{* * *}$ \\
& $(0.00660)$ & $(0.00368)$ & $(0.00211)$ & $(0.00117)$ \\
Observations & $5,446,000$ & $1,527,000$ & $1,519,000$ & $1,519,000$ \\
R-squared & 0.658 & 0.972 & 0.983 & 0.872 \\
Years & $76-15$ & $05-15$ & $05-15$ & $05-15$ \\
Earnings Measure & LBD & LBD & W-2 & W-2 \\
Weighted & Yes & Yes & Yes & No \\
Market FEs & Yes & Yes & Yes & Yes \\
CZ by Year FEs & Yes & Yes & Yes & Yes \\
\hline
\end{tabular}

Source: Longitudinal Business Database, 1976-2015; Form W-2, 2005-2015 Note: Table reports OLS regression estimates of the effect of local industrial concentration, as measured by the HHI, on log mean earnings. Earnings measures are constructed using either employment and payroll data from the LBD or earnings data from Form W-2, as indicated. Columns represent separate regressions, which include the indicated years of data and fixed effects. Regressions are employment-weighted as indicated. Coefficients represent elasticities. Sample sizes and statistic values have been rounded for disclosure avoidance. 
Table 3: First Stage Regressions

\begin{tabular}{|c|c|c|c|c|c|}
\hline VARIABLES & (1) & (2) & (3) & (4) & (5) \\
\hline & \multicolumn{5}{|c|}{ 1976-2015, LBD Sample } \\
\hline $\log \left(H H I^{-m}\right)$ & $\begin{array}{l}1.064 * * * \\
(0.0120)\end{array}$ & $\begin{array}{c}0.748 * * * \\
(0.0201)\end{array}$ & $\begin{array}{c}0.829 * * * \\
(0.0174)\end{array}$ & $\begin{array}{c}0.827^{* * *} \\
(0.0173)\end{array}$ & $\begin{array}{c}0.466^{* * *} \\
(0.0166)\end{array}$ \\
\hline Observations & $5,450,000$ & $5,450,000$ & $5,446,000$ & $5,446,000$ & $5,446,000$ \\
\hline R-squared & 0.504 & 0.773 & 0.930 & 0.932 & 0.956 \\
\hline F-stat & 7824 & 1389 & 2265 & 2284 & 791 \\
\hline & \multicolumn{5}{|c|}{ 2005-2015, LBD Sample } \\
\hline $\log \left(H H I^{-m}\right)$ & $\begin{array}{l}1.062 * * * \\
(0.0130)\end{array}$ & $\begin{array}{c}-0.328 * * * \\
(0.0786)\end{array}$ & $\begin{array}{c}0.503 * * * \\
(0.0303)\end{array}$ & $\begin{array}{c}0.505^{* * *} \\
(0.0300)\end{array}$ & $\begin{array}{c}0.192 * * * \\
(0.0226)\end{array}$ \\
\hline Observations & $1,531,000$ & $1,531,000$ & $1,527,000$ & $1,527,000$ & $1,527,000$ \\
\hline R-squared & 0.537 & 0.792 & 0.974 & 0.974 & 0.985 \\
\hline F-stat & 6667 & 17 & 276 & 284 & 73 \\
\hline & \multicolumn{5}{|c|}{ 2005-2015, W-2 Sample } \\
\hline $\log \left(H H I^{-m}\right)$ & $\begin{array}{c}1.053^{* * *} \\
(0.0128)\end{array}$ & $\begin{array}{c}-0.131^{* *} \\
(0.0640)\end{array}$ & $\begin{array}{c}0.505^{* * *} \\
(0.0280)\end{array}$ & $\begin{array}{c}0.505^{* * *} \\
(0.0274)\end{array}$ & $\begin{array}{r}0.187^{* * *} \\
(0.0204)\end{array}$ \\
\hline Observations & $1,522,000$ & $1,522,000$ & $1,519,000$ & $1,519,000$ & $1,519,000$ \\
\hline R-squared & 0.540 & 0.801 & 0.975 & 0.975 & 0.986 \\
\hline F-stat & 6747 & 4 & 326 & 339 & 84 \\
\hline Year FEs & No & Yes & Yes & No & No \\
\hline CZ FEs & No & Yes & No & No & No \\
\hline Industry FEs & No & Yes & No & No & No \\
\hline Market FEs & No & No & Yes & Yes & Yes \\
\hline CZ by Year FEs & No & No & No & Yes & Yes \\
\hline Market Trends & No & No & No & No & Yes \\
\hline
\end{tabular}

Source: Longitudinal Business Database, 1976-2015

Note: Table reports regression estimates of the relationship between local industrial concentration, as measured by the $\mathrm{HHI}$, and its instrument, the leaveone-out mean of the HHI across other markets in the same industry. Columns represent separate regressions, which include the indicated fixed effects in addition to the instrument. Regressions are employment-weighted. Coefficients represent elasticities. Sample sizes and statistic values have been rounded for disclosure avoidance. 
Table 4: Effects of Industrial Concentration on Mean Earnings

\begin{tabular}{lcccc}
\hline VARIABLES & $(1)$ & $(2)$ & $(3)$ & $(4)$ \\
\hline $\log (\mathrm{HHI})$ & & & & \\
& $-0.0512^{* *}$ & -0.00857 & $-0.0324^{* * *}$ & $-0.109^{* * *}$ \\
& $(0.0200)$ & $(0.0122)$ & $(0.0117)$ & $(0.0121)$ \\
Observations & $5,446,000$ & $1,527,000$ & $1,519,000$ & $1,519,000$ \\
R-squared & 0.657 & 0.972 & 0.983 & 0.871 \\
Years & $76-15$ & $05-15$ & $05-15$ & $05-15$ \\
Earnings Measure & LBD & LBD & W-2 & W-2 \\
Weighted & Yes & Yes & Yes & No \\
Market FEs & Yes & Yes & Yes & Yes \\
CZ by Year FEs & Yes & Yes & Yes & Yes \\
\hline
\end{tabular}

Source: Longitudinal Business Database, 1976-2015; Form W-2, 20052015

Note: Table reports instrumental variables regression estimates of the effect of local industrial concentration, as measured by the HHI, on log mean earnings. Earnings measures are constructed using either employment and payroll data from the LBD or earnings data from Form $\mathrm{W}-2$, as indicated. Columns represent separate regressions, which include the indicated years of data and fixed effects. Regressions are employment- weighted as indicated. Coefficients represent elasticities. Sample sizes and statistic values have been rounded for disclosure avoidance. 
Table 5: Effects of Industrial Concentration on Earnings Inequality

\begin{tabular}{lcccc}
\hline & $(1)$ & $(2)$ & $(3)$ & $(4)$ \\
VARIABLES & $90 / 10$ & $50 / 10$ & $90 / 50$ & Gini \\
\hline & & & & \\
$\log (\mathrm{HHI})$ & $0.173^{* * *}$ & $0.107^{* * *}$ & $0.0659^{* * *}$ & $0.0124^{* * *}$ \\
& $(0.0265)$ & $(0.0210)$ & $(0.0123)$ & $(0.00273)$ \\
& & & & \\
Observations & $1,519,000$ & $1,519,000$ & $1,519,000$ & $1,519,000$ \\
R-squared & 0.895 & 0.841 & 0.880 & 0.940 \\
Market FEs & Yes & Yes & Yes & Yes \\
CZ by Year FEs & Yes & Yes & Yes & Yes \\
\hline
\end{tabular}

Source: Longitudinal Business Database and Form W-2, 2005-2015 Note: Table reports instrumental variables regression estimates of the effect of local industrial concentration, as measured by the HHI, on measures of earnings inequality, constructed using earnings data from Form W-2. The dependent variables are the logs of the ratios of the 90th and 10th (Column 1), 50th and 10th (Column 2), or 90th and 50th (Column 3) percentiles of the earnings distribution, and the Gini coefficient (Column 4). Columns represent separate regressions, which include the indicated years of data and fixed effects. Regressions are employment-weighted as indicated. Coefficients in columns 1-3 represent elasticities, while the coefficient in column 4 is a semi-elasticity. Sample sizes and statistic values have been rounded for disclosure avoidance. 
Table 6: Effects of Industrial Concentration on Earnings Outcomes, Combined Non-Tradable and Construction Sector

\begin{tabular}{lcccccc}
\hline & $(1)$ & $\begin{array}{c}(2) \\
\text { Mean }\end{array}$ & $(3)$ & $(4)$ & $(5)$ & $(6)$ \\
VARIABLES & HHI & $\begin{array}{c}\text { Earnings } \\
\text { VAf }\end{array}$ & $90 / 10$ & $90 / 50$ & $50 / 10$ & Gini \\
\hline & & & & & & \\
$\left.\log (\mathrm{HHI})^{-m}\right)$ & $0.344^{* * *}$ & & & & & \\
& $(0.0285)$ & & & & & \\
& & $-0.184^{* * *}$ & $0.396^{* * *}$ & $0.0976^{* * *}$ & $0.298^{* * *}$ & $0.0148^{* * *}$ \\
Observations & 333,000 & 333,000 & 333,000 & 333,000 & 333,000 & 333,000 \\
R-squared & 0.976 & 0.970 & 0.867 & 0.936 & 0.767 & 0.933 \\
Market FEs & Yes & Yes & Yes & Yes & Yes & Yes \\
CZ by Year FEs & Yes & Yes & Yes & Yes & Yes & Yes \\
F-stat & 145.0 & & & & & \\
\hline
\end{tabular}

Source: Longitudinal Business Database and Form W-2, 2005-2015

Note: Table reports instrumental variables regression estimates of the effect of local industrial concentration, as measured by the HHI, on measures of earnings and inequality, constructed using earnings data from Form W-2, within the combined non-tradable and construction sector, as defined by Mian and Sufi (2014). The first column reports the first-stage regression. In the subsequent columns, the dependent variables are the log of mean earnings (Column 2), the logs of the ratios of the 90th and 10th (Column 3), 50th and 10th (Column 4), or 90th and 50th (Column 5) percentiles of the earnings distribution, and the Gini coefficient (Column 6). Columns represent separate regressions, which include the indicated years of data and fixed effects. Regressions are employment-weighted. Coefficients in columns 2-5 represent elasticities, while the coefficient in column 6 is a semi-elasticity. Sample sizes and statistic values have been rounded for disclosure avoidance. 
Table 7: HHI Exposure by Demographics

\begin{tabular}{cccccc}
\hline & \multicolumn{2}{c}{2005} & \multicolumn{2}{c}{2015} \\
& People & HHI & People & HHI & $\Delta$ HHI \\
\hline Male & $71,550,000$ & 0.1511 & $76,910,000$ & 0.1512 & 0.0001 \\
Female & $68,980,000$ & 0.1408 & $74,150,000$ & 0.1375 & -0.0033 \\
Age $<25$ & $25,920,000$ & 0.1218 & $26,110,000$ & 0.1217 & -0.0001 \\
Age 25-54 & $91,140,000$ & 0.1491 & $92,320,000$ & 0.1452 & -0.0039 \\
Age 55+ & $23,490,000$ & 0.1609 & $32,640,000$ & 0.1605 & -0.0004 \\
White & $96,610,000$ & 0.1538 & $95,980,000$ & 0.1552 & 0.0014 \\
Black & $15,680,000$ & 0.1501 & $17,530,000$ & 0.1483 & -0.0018 \\
Hispanic & $15,880,000$ & 0.1142 & $19,850,000$ & 0.1141 & -0.0001 \\
Low education & $11,720,000$ & 0.1702 & $8,469,000$ & 0.1736 & 0.0034 \\
High education & $20,300,000$ & 0.1588 & $16,660,000$ & 0.1617 & 0.0029 \\
\hline
\end{tabular}

Source: Longitudinal Business Database, Form W-2, and American Community Survey, 2005 through 2015; Decennial Census, 2000 and 2010; Census Numident.

Note: The White and Black categories refer to non-Hispanic White and non-Hispanic Black. The Hispanic category includes Hispanics of any race. The "low education" category includes individuals with a high school diploma or less, while the "high education" category includes individuals who have at least attended some college. Estimates have been rounded for disclosure avoidance. 